\title{
Linking the river to the estuary: influence of river discharge on tidal damping
}

\author{
H. Cai ${ }^{1}$, H. H. G. Savenije ${ }^{1}$, and M. Toffolon ${ }^{2}$ \\ ${ }^{1}$ Department of Water Management, Faculty of Civil Engineering and Geosciences, Delft University of Technology, \\ Stevinweg 1, P.O. Box 5048, 2600 GA Delft, the Netherlands \\ ${ }^{2}$ Department of Civil, Environmental and Mechanical Engineering, University of Trento, Trento, Italy
}

Correspondence to: H. Cai (h.cai@tudelft.nl)

Received: 26 June 2013 - Published in Hydrol. Earth Syst. Sci. Discuss.: 15 July 2013

Revised: 12 December 2013 - Accepted: 15 December 2013 - Published: 22 January 2014

\begin{abstract}
The effect of river discharge on tidal damping in estuaries is explored within one consistent theoretical framework where analytical solutions are obtained by solving four implicit equations, i.e. the phase lag, the scaling, the damping and the celerity equation. In this approach the damping equation is obtained by subtracting the envelope curves of high water and low water occurrence, taking into account that the flow velocity consists of a tidal and river discharge component. Different approximations of the friction term are considered in deriving the damping equation, resulting in as many analytical solutions. In this framework it is possible to show that river discharge affects tidal damping primarily through the friction term. It appears that the residual slope, due to nonlinear friction, can have a substantial influence on tidal wave propagation when including the effect of river discharge. An iterative analytical method is proposed to include this effect, which significantly improved model performance in the upper reaches of an estuary. The application to the Modaomen and Yangtze estuaries demonstrates that the proposed analytical model is able to describe the main tidal dynamics with realistic roughness values in the upper part of the estuary where the ratio of river flow to tidal flow amplitude is substantial, while a model with negligible river discharge can be made to fit observations only with unrealistically high roughness values.
\end{abstract}

\section{Introduction}

The natural variability of river flow into estuaries is greatly modified by human activities, such as dam construction, flow diversion and freshwater withdrawal. These activities impact on tidal damping and tidal wave propagation. In addition, they influence salt intrusion and even storm surge propagation into an estuary (Zhang et al., 2011, 2012; Cai et al., 2012b). Hence, understanding the effect of river discharge on tidal hydraulics is important. Most studies on the analytical solution of tidal wave propagation neglect the effect of river discharge, such as Hunt (1964), Dronkers (1964), Ippen (1966), Friedrichs and Aubrey (1994), Savenije (1998, 2001), Lanzoni and Seminara (1998), Prandle (2003), Savenije et al. (2008), Toffolon and Savenije (2011), Van Rijn (2011) and Cai et al. (2012a). Only few studies analysed the influence of river discharge on tidal wave propagation in estuaries. Of these, most authors used perturbation analysis, where the scaled equations are simplified by neglecting higher-order terms, generally discarding the advective acceleration term and linearizing the friction term (e.g. Dronkers, 1964; Leblond, 1978; Godin, 1985, 1999; Jay, 1991). Others used a regression model to determine the relationship between river discharge and tide (Jay et al., 2011; Kukulka and Jay, 2003). In contrast, Horrevoets et al. (2004) and Cai et al. (2012b) provided analytical solutions of tidal damping accounting for the effect of river discharge without simplifying the equations, based on the envelope method originally developed by Savenije (1998). 

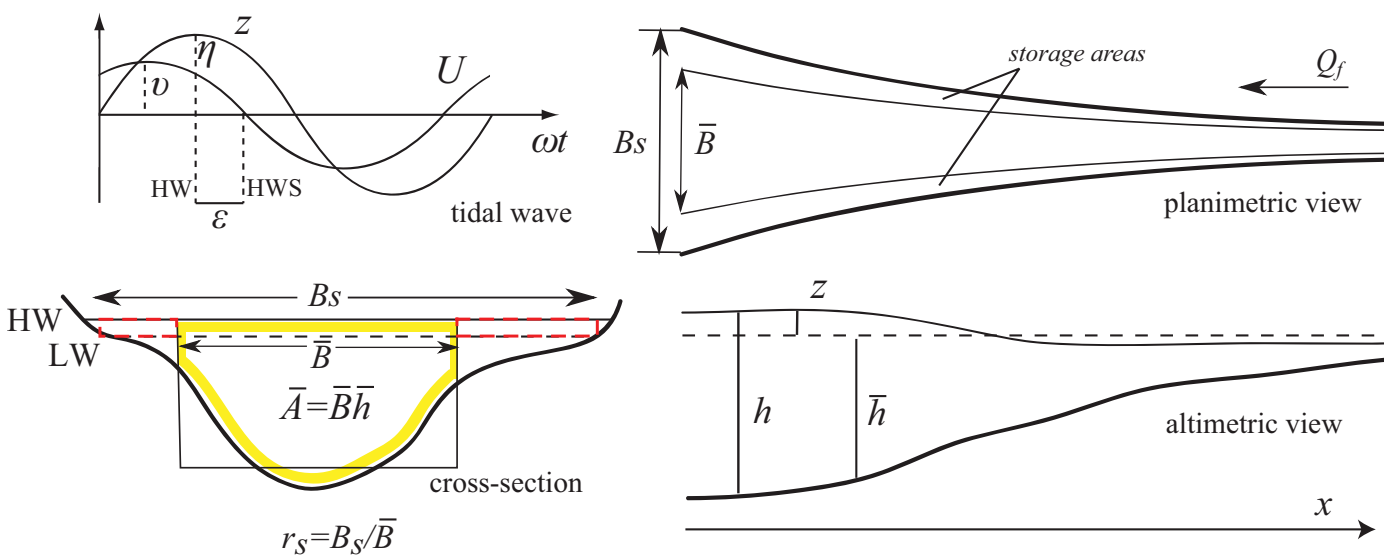

Fig. 1. Sketch of the estuary geometry and basic notations (after Savenije et al., 2008).

The treatment of the nonlinear friction term is key to finding an analytical solution for tidal hydrodynamics. The nonlinearity of the friction term has two sources: the quadratic stream velocity in the numerator and the variable hydraulic radius in the denominator (Parker, 1991). The classical linearization of the friction term was first obtained by Lorentz (1926) who, disregarding the variable depth, equated the dissipation by the linear friction over the tidal cycle to that of the quadratic friction. An extension to include river discharge was provided by Dronkers (1964). In this seminal work, he derived a higher-order formulation using Chebyshev polynomials, both with and without river discharge, resulting in a close correspondence with the quadratic velocity. Godin $(1991,1999)$ showed that quadratic velocity can be well approximated by using only the first- and third-order terms of the non-dimensional velocity. However, none of the above linearizations took into account the effect of the periodic variation of the hydraulic radius (to the power $4 / 3$ in the Manning-Strickler formulation) in the denominator of the friction term. On the other hand, Savenije (1998), using the envelope method (see Appendix A), obtained a damping equation that takes account of both the quadratic velocity and the time-variable hydraulic radius in the denominator.

This paper builds on a variety of previous publications on analytical approaches to tidal wave propagation and damping. A first attempt to include the effect of river discharge by Horrevoets et al. (2004) used the quasi-nonlinear method of Savenije (2001), assuming constant velocity amplitude, wave celerity and phase lag. Cai et al. (2012b) applied this model to the Modaomen estuary. In the present paper we make use of the analytical framework for tidal wave propagation by Cai et al. (2012a), but including for the first time the effect of river discharge in a hybrid model that performs better. Moreover, fully analytical equations accounting for four spatial variables (velocity amplitude, tidal amplitude, wave celerity and phase lag) of tidal propagation are now presented, demonstrating that the effect of river discharge is similar to that of friction. In addition, building on the research by Vignoli et al. (2003) on nonlinear frictional residual effects on tidal propagation, the influence of residual slope on tidal wave propagation has been taken into account, which significantly improved performance, especially in the upstream part of estuaries where the effect of river discharge is considerable.

In the following section, we introduce the relevant dimensionless parameters that control tidal hydrodynamics. The analytical framework for tidal wave propagation is summarized in Sect. 3. The damping equations that take account of river discharge are presented in Sect. 4 and the method to include the residual slope in the analytical solution is reported in Sect. 5. Section 6 presents a comparison of the different analytical approaches and a sensitivity analysis. The model is subsequently compared against the fully nonlinear numerical results and applied to two real estuaries where the effect of the river discharge is apparent in the upstream part of the estuary. The paper closes off with conclusions in Sect. 7.

\section{Formulation of the problem}

We consider a tidal channel with varying width and depth, a mostly rectangular cross section and lateral storage areas described by the storage width ratio $r_{\mathrm{S}}=B_{\mathrm{S}} / \bar{B}$, which is the ratio between the storage width $B_{\mathrm{S}}$ and the average stream width $\bar{B}$ (hereafter overbars denote tidal averages). The geometry of the idealized tidal channel is described in Fig. 1, together with a simplified picture of the periodic oscillations of water level and velocity defining the phase lag. It is generally accepted that the main geometric parameters of alluvial estuaries (tidally averaged cross-sectional area, width and depth) can be well described by exponential functions (e.g. Savenije, 1992):

$\bar{A}=\overline{A_{0}} \exp \left(-\frac{x}{a}\right), \quad \bar{B}=\overline{B_{0}} \exp \left(-\frac{x}{b}\right), \quad \bar{h}=\overline{h_{0}} \exp \left(-\frac{x}{d}\right)$,

where $x$ is the longitudinal coordinate directed landward, $\bar{A}$ and $\bar{h}$ are the tidally averaged cross-sectional area and 
Table 1. The definition of dimensionless parameters.

\begin{tabular}{ll}
\hline & Dimensionless parameters \\
\hline Independent & Dependent \\
\hline & Damping number \\
& $\left.\delta=c_{0} \mathrm{~d} \zeta / \zeta \omega \mathrm{d} x\right)$ \\
Tidal amplitude at the downstream boundary & Velocity number \\
$\zeta_{0}=\eta_{0} / \bar{h}$ & $\mu=v /\left(r_{\mathrm{S}} \zeta c_{0}\right)=v \bar{h} /\left(r_{\mathrm{S}} \eta c_{0}\right)$ \\
Estuary shape number & Celerity number \\
$\gamma=c_{0} /(\omega a)$ & $\lambda=c_{0} / c$ \\
Reference friction number & Phase lag \\
$\chi_{0}=r_{\mathrm{S}} g c_{0} /\left(K^{2} \omega \bar{h}^{4 / 3}\right)$ & $\varepsilon=\pi / 2-\left(\phi_{z}-\phi_{U}\right)$ \\
& Tidal amplitude \\
& $\zeta=\eta / \bar{h}$ \\
& Friction number \\
& $\chi=\chi_{0} \zeta\left[1-(4 \zeta / 3)^{2}\right]^{-1}=r_{\mathrm{S}} f c_{0} \zeta /(\omega \bar{h})$ \\
\hline
\end{tabular}

flow depth, $a, b, d$ are the convergence length of the crosssectional area, width, and depth, respectively, and the subscript 0 relates to the reference point near the estuary mouth. It follows from $\bar{A}=\bar{B} \bar{h}$ that $a=b d /(b+d)$.

The one-dimensional hydrodynamic equations in an alluvial estuary are given by (e.g. Savenije, 2005, 2012)

$$
\begin{aligned}
& \frac{\partial U}{\partial t}+U \frac{\partial U}{\partial x}+g \frac{\partial h}{\partial x}+g I_{\mathrm{b}}+g F+\frac{g h}{2 \rho} \frac{\partial \rho}{\partial x}=0, \\
& r_{\mathrm{s}} \frac{\partial h}{\partial t}+U \frac{\partial h}{\partial x}+h \frac{\partial U}{\partial x}+\frac{h U}{\bar{B}} \frac{\partial \bar{B}}{\partial x}=0,
\end{aligned}
$$

where $t$ is the time, $U$ is the cross-sectional average flow velocity, $h$ is the flow depth, $g$ is the gravitational acceleration, $I_{\mathrm{b}}$ is the bottom slope, $\rho$ is the water density and $F$ is the friction term, defined as

$F=\frac{U|U|}{K^{2} h^{4 / 3}}$,

where $K$ is the Manning-Strickler friction coefficient.

If we define the water level variation $z=h-\bar{h}$, then for a small tidal amplitude to depth ratio, we find

$U \frac{\partial h}{\partial x}=U \frac{\partial(z+\bar{h})}{\partial x}=U \frac{\partial z}{\partial x}+\frac{\bar{h} U}{\bar{h}} \frac{\partial \bar{h}}{\partial x} \approx U \frac{\partial z}{\partial x}+\frac{h U}{\bar{h}} \frac{\partial \bar{h}}{\partial x}$.

Substituting Eq. (5) into Eq. (3) and making use of Eq. (1), the following equation is obtained:

$r_{\mathrm{S}} \frac{\partial z}{\partial t}+U \frac{\partial z}{\partial x}+h \frac{\partial U}{\partial x}-\frac{h U}{a}=0$

which has the advantage that the depth convergence is implicitly taken into account by the convergence of the tidally averaged cross-sectional area.

The system is forced by a harmonic tidal wave with a tidal period $T$ and a frequency $\omega=2 \pi / T$ at the mouth of the estuary. As schematically shown in Fig. 1, the amplitudes of the tidal water level $z$ and velocity $U$ are represented by the variables of $\eta$ and $v$, respectively. The phases of the water level and velocity oscillations are indicated by $\phi_{z}$ and $\phi_{U}$, respectively. In a Lagrangean approach, we assume that the water particle moves according to a simple harmonic wave and the influence of river discharge on tidal velocities is not negligible. As a result, the instantaneous flow velocity $V$ for a moving particle is made up of a steady component $U_{\mathrm{r}}$, created by the discharge of freshwater, and a time-dependent component $U_{\mathrm{t}}$, contributed by the tide:

$V=U_{\mathrm{t}}-U_{\mathrm{r}}, \quad U_{\mathrm{t}}=v \sin (\omega t), \quad U_{\mathrm{r}}=Q_{\mathrm{f}} / \bar{A}$,

where $Q_{\mathrm{f}}$ is the freshwater discharge, directed against the positive $x$-direction.

It can be shown that the estuarine hydrodynamics is controlled by three dimensionless parameters in the case of negligible river discharge (Toffolon et al., 2006; Savenije et al., 2008; Toffolon and Savenije, 2011; Cai et al., 2012a). Table 1 presents these independent dimensionless parameters that depend on the geometry and external forcing. They are: $\zeta_{0}$ the dimensionless tidal amplitude at the downstream boundary, $\gamma$ the estuary shape number (representing the effect of cross-sectional area convergence and depth), and $\chi_{0}$ the reference friction number (describing the frictional dissipation). These parameters contain $c_{0}$, representing the classical wave celerity of a frictionless progressive wave in a constant-width channel:

$c_{0}=\sqrt{g \bar{h} / r_{\mathrm{S}}}$.

The six dependent dimensionless variables are also presented in Table 1 . They are: $\delta$ the damping number (a dimensionless description of the rate of increase, $\delta>0$, or decrease, $\delta<0$, of the tidal wave amplitude along the estuary), $\mu$ the velocity number (the actual velocity scaled with the frictionless value in a prismatic channel), $\lambda$ the celerity number (the 
Table 2. Analytical framework for tidal wave propagation (Cai et al., 2012a).

\begin{tabular}{|c|c|c|c|c|c|}
\hline Case & & Phase lag $\tan (\varepsilon)$ & Scaling $\mu$ & Celerity $\lambda^{2}$ & Damping $\delta$ \\
\hline General & $\begin{array}{l}\text { Quasi-nonlinear } \\
\text { Linear } \\
\text { Dronkers } \\
\text { Hybrid }\end{array}$ & $\lambda /(\gamma-\delta)$ & $\cos (\varepsilon) /(\gamma-\delta)$ & $1-\delta(\gamma-\delta)$ & $\begin{array}{l}\gamma / 2-\chi \mu^{2} / 2 \\
\gamma / 2-4 \chi \mu /(3 \pi \lambda) \\
\gamma / 2-8 \chi \mu /(15 \pi \lambda)-16 \chi \mu^{3} \lambda /(15 \pi) \\
\gamma / 2-4 \chi \mu^{2} /(9 \pi \lambda)-\chi \mu^{2} / 3\end{array}$ \\
\hline Constant cross-section & $\begin{array}{l}\text { Quasi-nonlinear } \\
\text { Linear } \\
\text { Dronkers } \\
\text { Hybrid }\end{array}$ & $-\lambda / \delta$ & $-\cos (\varepsilon) / \delta$ & $1+\delta^{2}$ & $\begin{array}{l}-\chi \mu^{2} / 2 \\
-4 \chi \mu /(3 \pi \lambda) \\
-8 \chi \mu /(15 \pi \lambda)-16 \chi \mu^{3} \lambda /(15 \pi) \\
-4 \chi \mu^{2} /(9 \pi \lambda)-\chi \mu^{2} / 3\end{array}$ \\
\hline Frictionless $(\gamma<2)$ & & $\sqrt{4 / \gamma^{2}-1}$ & 1 & $1-\gamma^{2} / 4$ & $\gamma / 2$ \\
\hline Frictionless $(\gamma \geq 2)$ & & 0 & $\left(\gamma-\sqrt{\gamma^{2}-4}\right) / 2$ & 0 & $\left(\gamma-\sqrt{\gamma^{2}-4}\right) / 2$ \\
\hline Ideal estuary & & $1 / \gamma$ & $\sqrt{1 /\left(1+\gamma^{2}\right)}$ & 1 & 0 \\
\hline
\end{tabular}

ratio between the theoretical frictionless celerity in a prismatic channel and the actual wave celerity), $\varepsilon$ the phase lag between high water (HW) and high water slack (HWS) or between low water (LW) and low water slack (LWS), $\zeta$ the dimensionless tidal amplitude that varies along the estuary, and finally $\chi$ the friction number as a function of $\zeta$ (Toffolon et al., 2006; Savenije et al., 2008). The friction number contains $f$ as the dimensionless friction factor resulting from the envelope method (Savenije, 1998):

$f=\frac{g}{K^{2} \bar{h}^{1 / 3}}\left[1-(4 \zeta / 3)^{2}\right]^{-1}$,

where the factor 4/3 stems from a Taylor approximation of the exponent of the hydraulic radius in the friction term.

\section{Analytical framework for tidal wave propagation with no river discharge}

For negligible river discharge, the analytical solution of the one-dimensional hydrodynamic equations is obtained by solving four implicit equations, i.e. the phase lag, the scaling, the celerity and the damping equation (Savenije et al., 2008). The phase lag and scaling equations were derived from the mass balance equation by Savenije $(1992,1993)$ using a Lagrangean approach. The celerity equation was developed by Savenije and Veling (2005) using a method of characteristics. The damping equation can be obtained through various methods. Savenije $(1998,2001)$ introduced the envelope method that retains the nonlinear friction term, by subtracting the envelopes at $\mathrm{HW}$ and $\mathrm{LW}$.

Cai et al. (2012a) showed that different friction formulations can be used in the envelope method to arrive at an equal number of damping equations. In general, the main classes of the solutions are: (1) quasi-nonlinear solution with nonlinear friction term (Savenije et al., 2008); (2) linear solution with Lorentz's linearization (Lorentz, 1926); (3) Dronkers' solution with higher-order formulation for quadratic velocity (Dronkers, 1964); (4) hybrid solution characterized by a weighted average of Lorentz's linearization, with weight $1 / 3$, and the nonlinear friction term, with weight 2/3 (Cai et al., 2012a). In Table 2, we present the solutions of these four classes for the general case and for some particular cases, including constant cross-section $(\gamma=0)$, frictionless channel $(\chi=0$, both with subcritical convergence $(\gamma<2)$ and supercritical convergence $(\gamma \geq 2))$ and ideal estuary $(\delta=0)$. It was shown by Cai et al. $(2012 \mathrm{a})$ that the hybrid model provides the best predictions when compared with numerical solutions. Figure 2 shows the main dependent dimensionless parameters as function of the shape number $\gamma$ and the friction number $\chi$, obtained with the hybrid model.

\section{New damping equations accounting for the effect of river discharge}

In the following, we extend the validity of the damping equations by introducing the effect of river discharge into the different approximations of the friction term. The dimensionless river discharge $\varphi$ is defined as

$\varphi=\frac{U_{\mathrm{r}}}{v}$

We show the procedure for including the effect of river discharge within the envelope method in Appendix A.

For a more concise notation, we refer to a general formulation of the damping parameter of the form:

$\delta=\frac{\mu^{2}}{1+\mu^{2} \beta}(\gamma \theta-\chi \mu \lambda \Gamma)$,

where we introduce the dimensionless parameters $\beta, \theta$, and $\Gamma$. Both $\beta$ and $\theta$ are equal to unity if $\varphi=0$. The parameter $\beta$ corrects the tidal Froude number $\mu^{2}=\left[v /\left(c_{0} r_{\mathrm{S}} \zeta\right)\right]^{2}$ (Savenije et al., 2008) for the influence of river discharge: 

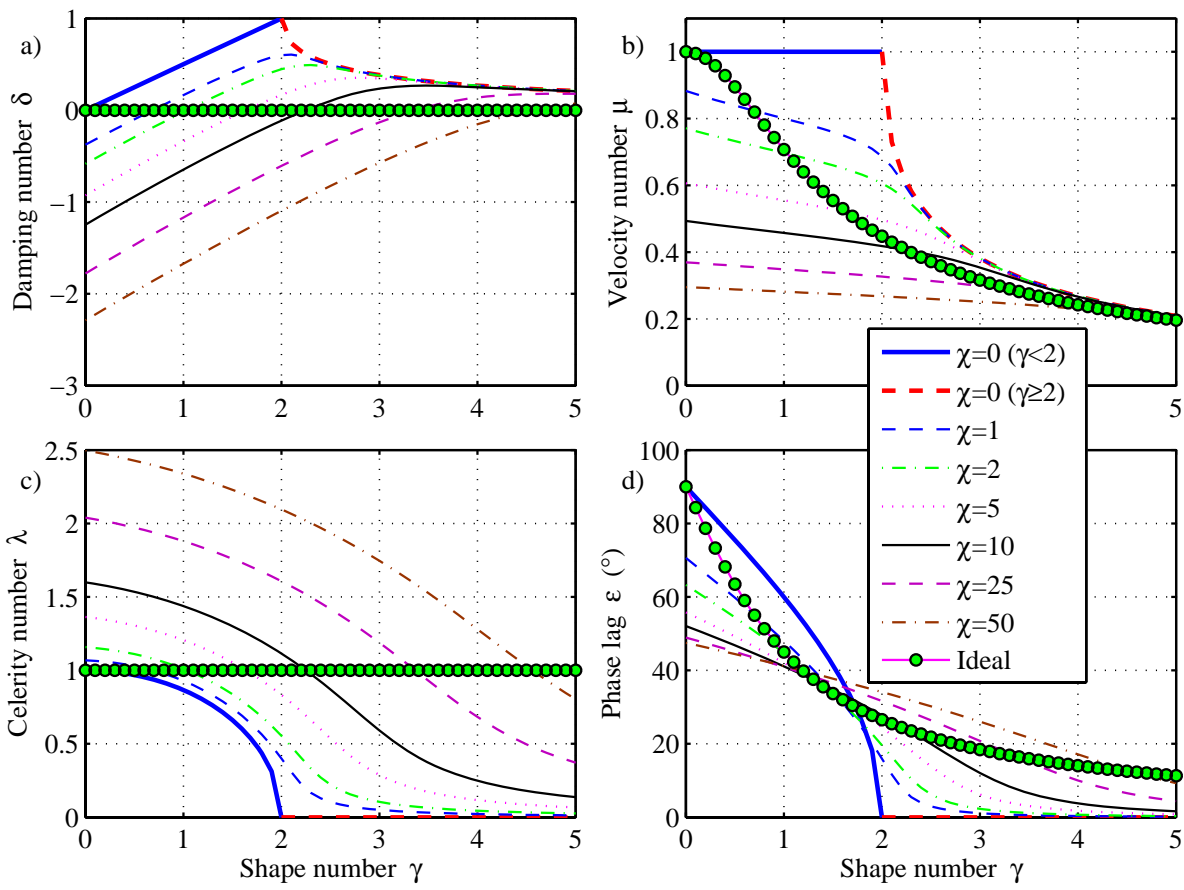

Fig. 2. Variation of damping number $\delta$, the velocity number $\mu$, celerity number $\lambda$ and phase lag $\varepsilon$ with the estuary shape number $\gamma$ for different values of the friction number $\chi$, obtained with the hybrid model. The green symbols represent the ideal estuary (see Table 2 ).

$\beta=\theta-r_{\mathrm{S}} \zeta \frac{\varphi}{\mu \lambda}$

The correction factor $\theta$ accounts for the wave celerity not being equal at $\mathrm{HW}$ and $\mathrm{LW}$, which depends on $\varphi$ by

$\theta=1-(\sqrt{1+\zeta}-1) \frac{\varphi}{\mu \lambda}$

This parameter has a value smaller than unity, but is close to unity as long as $\zeta \ll 1$ although $\mu \lambda=\sin (\varepsilon)$ is also less than 1 . In practical applications, we can typically assume $\theta \approx 1$, but this is not a necessary assumption in our method. Finally, the parameter $\Gamma$ depends on the specific approach, as it is discussed in the next sections.

\subsection{The quasi-nonlinear approach}

Savenije et al. (2008) presented a fully analytical solution for tidal wave propagation without linearizing the friction term through the envelope method. The method was termed quasi-nonlinear because it still made use of a regular harmonic function to describe the flow velocity. Horrevoets et al. (2004) introduced the effect of river discharge in the quasinonlinear model. Using the dimensionless parameters presented in Table 1, Cai et al. (2012b) developed this solution into a general expression for tidal damping, where two zones are distinguished depending on the value of $\varphi$ defined by Eq. (10).
In the tide-dominated zone, where $\varphi<\mu \lambda$, the parameter $\Gamma$ introduced in Eq. (11) reads

$\Gamma=\mu \lambda\left[1+\frac{8}{3} \zeta \frac{\varphi}{\mu \lambda}+\left(\frac{\varphi}{\mu \lambda}\right)^{2}\right]$,

while in the river discharge-dominated zone, where $\varphi \geq \mu \lambda$, it becomes

$$
\Gamma=\mu \lambda\left[\frac{4}{3} \zeta+2 \frac{\varphi}{\mu \lambda}+\frac{4}{3} \zeta\left(\frac{\varphi}{\mu \lambda}\right)^{2}\right] .
$$

\subsection{Lorentz's approach}

The Fourier expansion of the product $U|U|$ in the friction term is (Dronkers, 1964, 272-275)

$U|U|=\frac{1}{4} L_{0} v^{2}+\frac{1}{2} L_{1} v U_{\mathrm{t}}$,

where the expressions of coefficients $L_{0}$ and $L_{1}$ when $0<\varphi<1$ are

$$
\begin{aligned}
& L_{0}=[2+\cos (2 \alpha)]\left(2-\frac{4 \alpha}{\pi}\right)+\frac{6}{\pi} \sin (2 \alpha), \\
& L_{1}=\frac{6}{\pi} \sin (\alpha)+\frac{2}{3 \pi} \sin (3 \alpha)+\left(4-\frac{8 \alpha}{\pi}\right) \cos (\alpha),
\end{aligned}
$$

with

$\alpha=\arccos (-\varphi)$, 
Table 3. Comparison of the terms in the damping Eq. (11) for different analytical methods. The effect of the time-dependent depth in the friction term for Lorentz's, Dronkers' and Godin's method is accounted for by setting $\kappa=1$ in the expressions for $\Gamma$, whereas $\kappa=0$ describes the time-independent case.

\begin{tabular}{|c|c|c|c|c|}
\hline Model & Friction term & $\Gamma$ without river discharge $(\varphi=0)$ & $\Gamma$ with river discharge $(\varphi>0)$, introducing $\psi=\varphi /(\mu \lambda)$ & \\
\hline Savenije $\mathrm{a}^{\mathrm{a}, \mathrm{b}, \mathrm{c}, \mathrm{d}}$ & $\frac{U|U|}{K^{2} h^{4 / 3}}$ & $\mu \lambda$ & $\left\{\begin{array}{c}\mu \lambda\left(1+\frac{8}{3} \zeta \psi+\psi^{2}\right) \quad(\psi<1) \\
\mu \lambda\left(\frac{4}{3} \zeta+2 \psi+\frac{4}{3} \zeta \psi^{2}\right) \quad(\psi \geq 1)\end{array}\right.$ & $\mathrm{T} 1$ \\
\hline Lorentz $^{\mathrm{e}}$ & $\frac{1}{K^{2} h^{4 / 3}}\left(\frac{L_{0}}{4} v^{2}+\frac{L}{2} v U_{\mathrm{t}}\right)$ & $8 /(3 \pi)$ & $\frac{L_{1}}{2}-\kappa \zeta \frac{L_{0}}{3 \mu \lambda}$ & $\mathrm{T} 2$ \\
\hline Dronkers ${ }^{\mathrm{f}}$ & $\frac{1}{K^{2} h^{4 / 3}}\left(p_{0} v^{2}+p_{1} v U+p_{2} U^{2}+p_{3} U^{3} / v\right)$ & $\frac{16}{15 \pi}+\frac{32}{15 \pi}(\mu \lambda)^{2}$ & $\left\{\begin{array}{c}\frac{1}{\pi}\left\{-p_{0} \frac{4 \kappa \zeta}{3 \mu \lambda}+p_{1}\left(1+\frac{4}{3} \kappa \zeta \psi\right)\right. \\
-2 p_{2} \varphi\left[1+\frac{2}{3} \kappa \zeta\left(\frac{1}{\psi}+\psi\right)\right] \\
\left.+p_{3} \varphi^{2}\left[3+\frac{1}{\psi^{2}}+4 \kappa \zeta\left(\frac{1}{\psi}+\frac{\psi}{3}\right)\right]\right\}\end{array}\right.$ & $\mathrm{T} 3$ \\
\hline Godin ${ }^{g}$ & $\frac{16}{15 \pi} \frac{U^{\prime 2}}{K^{2} h^{4 / 3}}\left[\frac{U}{U^{\prime}}+2\left(\frac{U}{U^{\prime}}\right)^{3}\right]$ & $\frac{16}{15 \pi}+\frac{32}{15 \pi}(\mu \lambda)^{2}$ & $G_{0}+G_{1}(\mu \lambda)^{2}+\kappa \zeta\left(G_{2} \mu \lambda+\frac{G_{3}}{\mu \lambda}\right)$ & $\mathrm{T} 4$ \\
\hline \multirow[t]{2}{*}{ Hybrid $^{\text {h }}$} & $\frac{2}{3} \frac{U|U|}{K^{2} h^{4 / 3}}+\frac{1}{3} \frac{1}{K^{2} h^{4 / 3}}\left(\frac{L_{0}}{4} v^{2}+\frac{L_{1}}{2} v U_{\mathrm{t}}\right)$ & $\frac{2}{3} \mu \lambda+\frac{8}{9 \pi}$ & $\left\{\begin{array}{c}\frac{2}{3} \mu \lambda\left(1+\frac{8}{3} \zeta \psi+\psi^{2}\right)+\frac{L_{1}}{6}-\frac{L_{0}}{9} \frac{\zeta}{\mu \lambda} \quad(\psi<1) \\
\frac{2}{3} \mu \lambda\left(\frac{4}{3} \zeta+2 \psi+\frac{4}{3} \zeta \psi^{2}\right)+\frac{L_{1}}{6}-\frac{L_{0}}{9} \frac{\zeta}{\mu \lambda} \quad(\psi \geq 1)\end{array}\right.$ & T5 \\
\hline & & $\beta=1, \quad \theta=1$ & $\beta=\theta-r_{\mathrm{S}} \zeta \psi, \quad \theta \approx 1$ & \\
\hline
\end{tabular}

${ }^{\mathrm{a}}$ Savenije (1998); ${ }^{\mathrm{b}}$ Horrevoets et al. (2004); ${ }^{\mathrm{c}}$ Savenije et al. (2008); ${ }^{\mathrm{d}}$ Cai et al. (2012b); ${ }^{\mathrm{e}}$ Lorentz (1926); ${ }^{\mathrm{f}}$ Dronkers (1964); ${ }^{\mathrm{g}}$ Godin (1991, 1999); ${ }^{\mathrm{h}}$ Cai et al. (2012a)

where $\pi / 2<\alpha<\pi$ because $\varphi$ is positive. In case $\varphi \geq 1$,

$L_{0}=-2-4 \varphi^{2}, \quad L_{1}=4 \varphi$,

while the case of $\varphi=1$ (i.e. $U_{\mathrm{r}}=v$ ) corresponds with $\alpha=\pi$ and leads to $L_{0}=-6$ and $L_{1}=4$.

As a result, the development of the Lorentz's friction term accounting for the effect of river discharge reads

$F_{\mathrm{L}}=\frac{1}{K^{2} \bar{h}^{4 / 3}}\left(\frac{1}{4} L_{0} v^{2}+\frac{1}{2} L_{1} v U_{\mathrm{t}}\right)$,

where the subscript $\mathrm{L}$ stands for Lorentz.

If the river discharge is negligible, i.e. $U_{\mathrm{r}}=0$ and $\alpha=\pi / 2$, Eq. (21) reduces to the classical Lorentz linearization and hence $L_{0}=0$ and $L_{1}=16 /(3 \pi)$ :

$F_{\mathrm{L}}=\frac{8}{3 \pi} \frac{v}{K^{2} \bar{h}^{4 / 3}} U_{\mathrm{t}}$.

With the envelope method, making use of friction term Eq. (21), it is possible to derive the parameter $\Gamma$ in the damping Eq. (11) (see Appendix A):

$\Gamma_{\mathrm{L}}=\frac{L_{1}}{2}$.

Extending Lorentz's solution with the periodic variation of the depth in the denominator of the friction term (i.e. $K^{2} h^{4 / 3}$ ) is also possible. The resulting expression is reported in Table 3, where $\kappa=1$ yields the time-dependent case, while Eq. (20) is recovered by setting $\kappa=0$.

We also tested higher-order formulations of the friction term, such as proposed by Dronkers (1964) and Godin (1991, 1999), which we implemented in the envelope method arriving at tidal damping equations accounting for river discharge. For further details on these damping equations, readers can refer to the Supplement (see also Table 3).

\subsection{Hybrid method}

Cai et al. (2012a) showed that a linear combination of the traditional Lorentz approach (e.g. Toffolon and Savenije, 2011) with the quasi-nonlinear approach (e.g. Savenije et al., 2008) gives good predictive results. In this study, we expand this method to account for river discharge. Consequently, the new nonlinear friction term reads

$F_{\mathrm{H}}=\frac{2}{3} F+\frac{1}{3} F_{\mathrm{L}}=\frac{1}{K^{2} h^{4 / 3}}\left[\frac{2}{3} U|U|+\frac{1}{3}\left(\frac{L_{0}}{4} v^{2}+\frac{L_{1}}{2} v U_{\mathrm{t}}\right)\right]$,

where the subscript $\mathrm{H}$ stands for hybrid. Applying the envelope method with this friction formulation, we are able to derive a new river-discharge-dependent damping equation:

$\Gamma_{\mathrm{H}}=\frac{2}{3} \Gamma+\frac{1}{3} \Gamma_{\mathrm{L}}$,

where $\Gamma_{\mathrm{L}}$ is given by T2 (see Table 3 ) with $\kappa=1$, and $\Gamma$ by either Eq. (14) or (15) in the downstream tide-dominated zone $(\varphi<\mu \lambda)$ or in the upstream river discharge-dominated zone $(\varphi \geq \mu \lambda)$, respectively.

\section{Influence of nonlinear friction on the averaged water level}

The tidally averaged free surface elevation does not coincide with mean sea level along the estuary due to the nonlinear frictional effect on averaged water level, even if river discharge is negligible (Vignoli et al., 2003). Vignoli et al. (2003) derived an analytical expression for the mean free surface elevation (see Appendix B):

$\bar{z}(x)=-\int_{0}^{x} \overline{\frac{V|V|}{K^{2} h^{4 / 3}}} \mathrm{~d} x$, 
which is also valid when accounting for the effect of river discharge (the overbar denotes the average over the tidal period).

A fully nonlinear one-dimensional numerical model accounting for river discharge has been used to investigate the effects of the friction term on the tidally averaged water level. The numerical model uses an explicit MacCormack scheme and is second-order accurate both in space and time (Toffolon et al., 2006). As a simple case, we considered a channel with horizontal bed, where the width is assumed to decrease exponentially in landward direction as

$\bar{B}=\overline{B_{\min }}+\left(\overline{B_{0}}-\overline{B_{\min }}\right) \exp (-x / b)$,

where $\overline{B_{\min }}$ is imposed to keep a minimum width when the convergence is strong and the estuary is long. The length of the estuary is $2000 \mathrm{~km}$. In the landward part, we imposed a slight bed slope and higher friction in order to reduce spurious reflections due to the landward boundary condition.

Figure 3 presents a comparison between the numerically calculated, tidally averaged water level and the values obtained from Eq. (26), both with $\left(5000 \mathrm{~m}^{3} \mathrm{~s}^{-1}\right)$ and without river discharge. For simplicity, we calculated the tidally averaged friction using the Eulerian velocity $U$ rather than the Lagrangean velocity $V$ with $\left(5000 \mathrm{~m}^{3} \mathrm{~s}^{-1}\right)$ and without river discharge. It can be seen from Fig. 3 that the correspondence between them is reasonable. The deviation is mainly due to the fact that we calculated the tidally averaged friction using the Eulerian velocity $U$, instead of integrating the Lagrangean velocity $V$ as in Eq. (26). We can see from Fig. 3 that due to river discharge the residual water level slope is significantly increased, suggesting that the residual effects on the averaged water level is particularly important when river discharge is substantial.

\section{Results}

\subsection{Analytical solutions of the new models}

The different damping equations introduced above should be combined with the phase lag, scaling and celerity equations of Table 2, to form the system of the hydrodynamic equations:

$\tan (\varepsilon)=\frac{\lambda}{\gamma-\delta}$,

$\mu=\frac{\sin (\varepsilon)}{\lambda}=\frac{\cos (\varepsilon)}{\gamma-\delta}$,

$\lambda^{2}=1-\delta(\gamma-\delta)$.

In this way we have a new set of four implicit analytical equations that account for the effect of river discharge. As shown in Savenije et al. (2008), Eqs. (28) and (29) can be combined to eliminate the variable $\varepsilon$ to give

$(\gamma-\delta)^{2}=\frac{1}{\mu^{2}}-\lambda^{2}$.

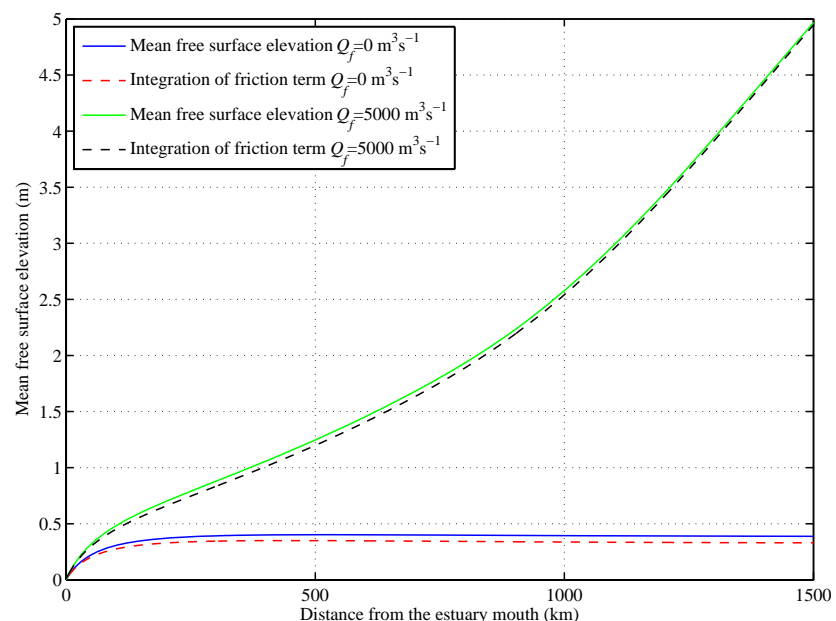

Fig. 3. Tidally averaged free surface elevation calculated from the numerical model (solid lines) and evaluated through Eq. (26) both with and without river discharge for given values of $K=60 \mathrm{~m}^{1 / 3} \mathrm{~s}^{-1}, \quad b=352 \mathrm{~km}, \zeta_{0}=0.2, \bar{h}=10 \mathrm{~m}, \overline{B_{0}}=5000 \mathrm{~m}$, $\overline{B_{\min }}=300 \mathrm{~m}$.

A fully explicit solution for the main dimensionless parameters (i.e. $\mu, \delta, \lambda, \varepsilon$ ) can be derived in some cases (Toffolon et al., 2006; Savenije et al., 2008), but an iterative procedure is needed to obtain the solution in general. The following procedure usually converges in a few steps: (1) initially we assume $Q_{\mathrm{f}}=0$ and calculate the initial values for the velocity number $\mu$, celerity number $\lambda$ and the tidal velocity amplitude $v$ (and hence dimensionless river discharge term $\varphi$ ) using the analytical solution proposed in Cai et al. (2012a) (see Sect. 3); (2) taking into account the effect of river discharge $Q_{\mathrm{f}}$, the revised damping number $\delta$, celerity number $\lambda$, velocity number $\mu$ and velocity amplitude $v$ (and hence $\varphi$ ) are calculated by solving Eqs. (11), (30) and (31) using a simple Newton-Raphson method; (3) this process is repeated until the result is stable and then the other parameters (e.g. $\varepsilon$, $\eta, v)$ are computed.

It is important to realize that the solutions for the dependent dimensionless parameters $\mu, \delta, \lambda$ and $\varepsilon$ are local solutions because they are obtained by the four implicit equations that depend on local quantities that vary along the estuary (i.e. the local tidal amplitude to depth ratio $\zeta$, the local estuary shape number $\gamma$ and the local friction number $\chi$ ). To reproduce wave propagation correctly along the estuary, a multi-reach approach has to be used to follow along-channel variation, dividing the estuary in a number of reaches (e.g. Toffolon and Savenije, 2011). With the damping number $\delta$, it is possible to calculate a tidal amplitude $\eta_{1}$ at a distance $\Delta x($ e.g. $1 \mathrm{~km})$ upstream by simple explicit integration of the damping number:

$\eta_{1}=\eta_{0}+\frac{\mathrm{d} \eta}{\mathrm{d} x} \Delta x=\eta_{0}+\frac{\eta_{0} \omega \delta}{c_{0}} \Delta x$. 

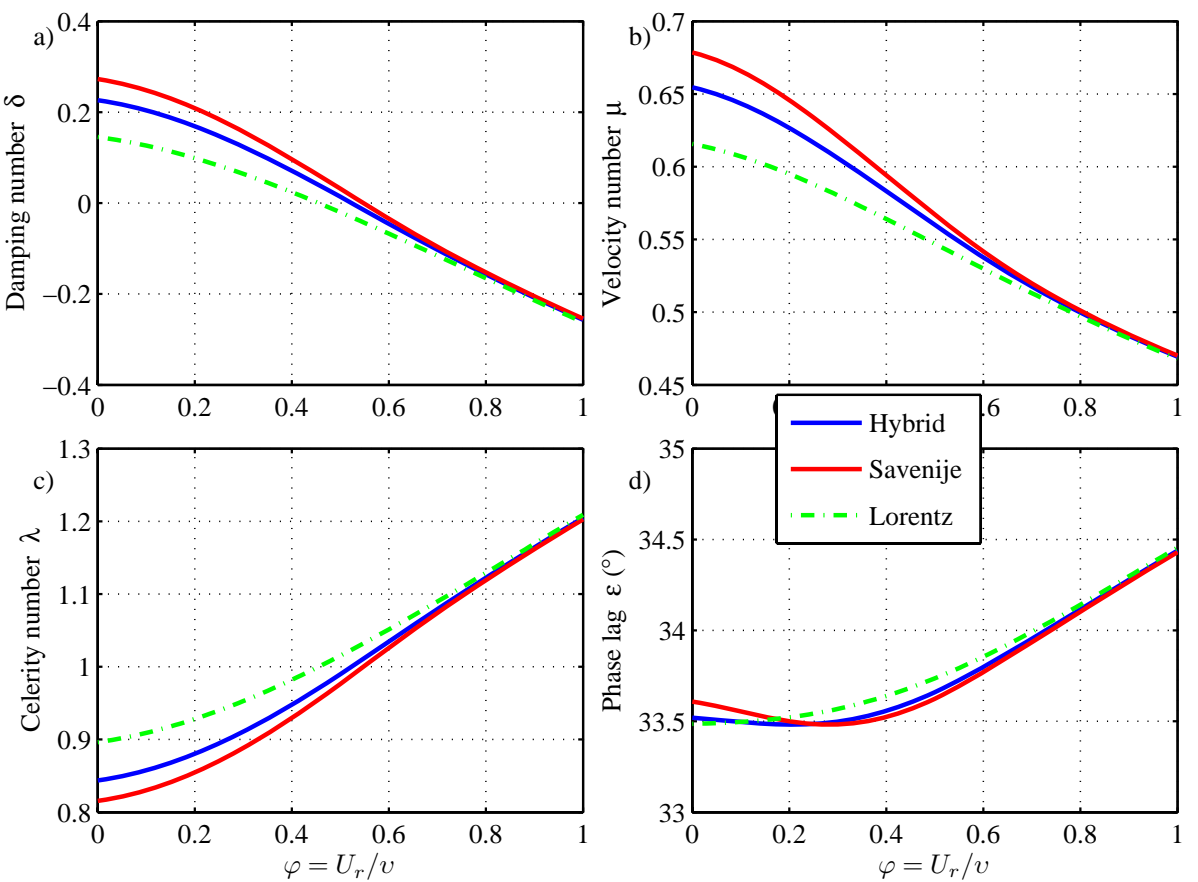

Fig. 4. The main dimensionless parameters (damping number $\delta$, velocity number $\mu$, celerity number $\lambda$ and phase lag $\varepsilon$ ) obtained with the different analytical methods as a function of dimensionless river discharge $\varphi$ with $\zeta_{0}=0.1, \gamma=1.5, \chi=20$ and $r_{\mathrm{S}}=1$.

In a Lagrangean reference frame, tidally averaged friction can be estimated by the average of friction at HW and LW, based on the assumption that the water particle moves according to a simple harmonic, yielding

$$
\overline{\frac{V|V|}{K^{2} h^{4 / 3}}} \approx \frac{1}{2}\left[\frac{V_{\mathrm{HW}}\left|V_{\mathrm{HW}}\right|}{K^{2}(\bar{h}+\eta)^{4 / 3}}+\frac{V_{\mathrm{LW}}\left|V_{\mathrm{LW}}\right|}{K^{2}(\bar{h}-\eta)^{4 / 3}}\right] .
$$

Substitution of different approximations of the friction term, described in the Sect. 4, into Eq. (33) and combination with Eq. (26) ends up with an equal number of analytical solutions for the tidally averaged depth along the estuary:

$\bar{h}_{\text {new }}(x)=\bar{h}(x)+\bar{z}(x)$,

which modifies the estuary shape number. Making use of Eq. (34) an iterative procedure can be applied to obtain the tidal dynamics along the estuary accounting for the effect of the residual water level slope.

\subsection{Comparison among different approaches}

Table 3 summarizes the damping equations with and without the effect of river discharge for the different friction formulations, leading to different forms of the damping equation. The substitution of $\varphi=0$ yields the same damping equations as in Table 2 (general case), as it can be derived by exploiting the phase lag and scaling equations (Cai et al., 2012a).

As an illustration, the relation between the dependent dimensionless parameters and the dimensionless river discharge $\varphi$ is shown in Fig. 4 for given values of $\zeta_{0}=0.1$, $\gamma=1.5, \chi=2$ and $r_{\mathrm{S}}=1$. We can see that for increasing river discharge all the analytical models approach the same asymptotic solution, which is due to the fact that the approximations to the quadratic velocity $U|U|$ is close to $U^{2}$ when the effect of tide is less important and the current no longer reverses. Actually, we can see that the parameter $\Gamma$ in the friction term in T1, T2 and T5 (see Table 3) tends to $(4 / 3) \zeta \varphi^{2} /(\mu \lambda)$ when $\varphi$ approaching infinity. Moreover, it can be seen from Fig. 4 that the performance of the hybrid model is close to the average of Lorentz's and the quasinonlinear method, which is to be expected since the hybrid tidal damping represents a weighted average of these two solutions. In addition, we note that the different methods tend to converge for large values of $\varphi$.

It is important to realize that the different approaches use different expressions for the dimensionless friction $f$ (i.e. Eq. 9) as a result of the variation of the depth over time. While the effect of a variable depth is taken into account in the envelope method, the original Lorentz method assumes a constant depth in the friction term, which is the same as considering $\zeta=0$ in Eq. (9):

$f_{0}=g /\left(K^{2} \bar{h}^{1 / 3}\right)$.

The damping equations accounting for time variability, which is related to the term $\zeta$ in Eq. (9), are presented in Table 3. 

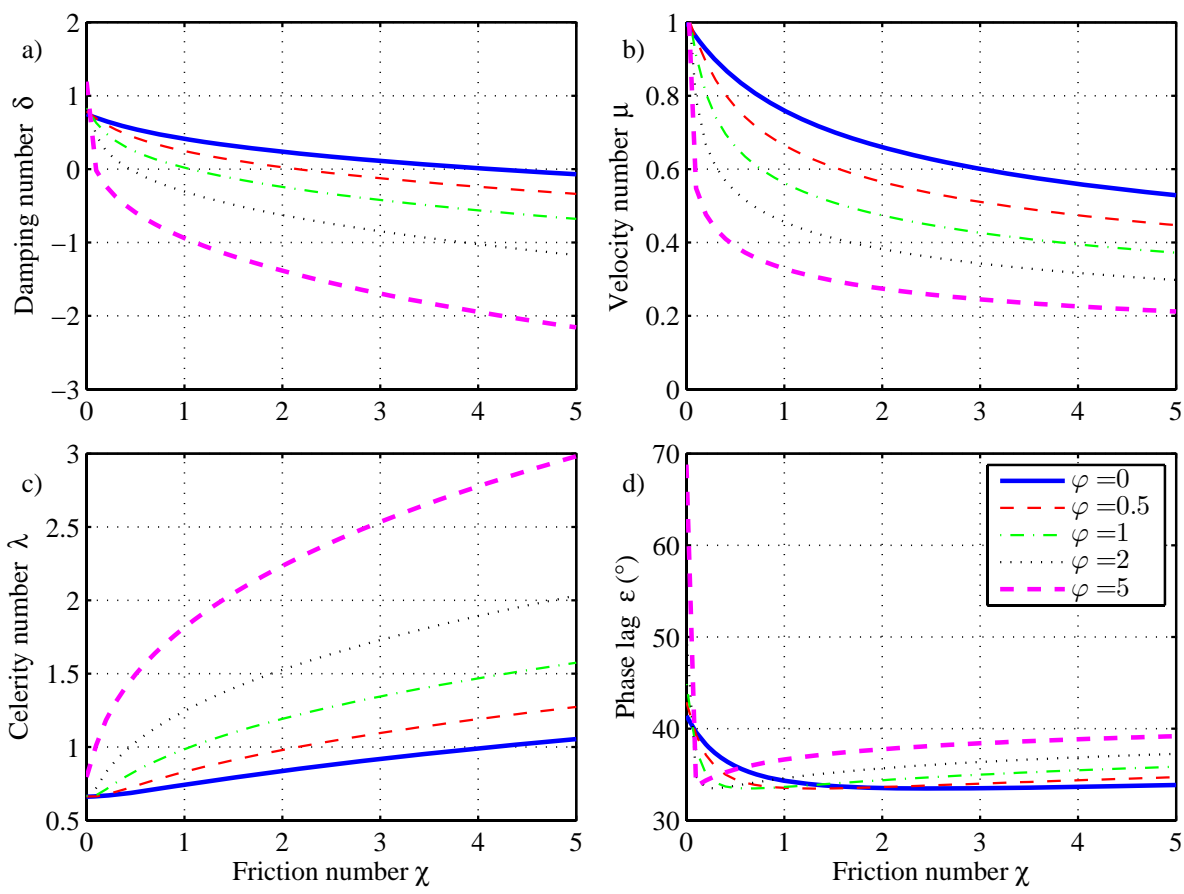

Fig. 5. Relationship between the main dimensionless parameters and the friction number $\chi$ obtained by solving Eqs. (11) (with $\Gamma=\Gamma_{\mathrm{H}}$ ), (30) and (31) for different values of the dimensionless river discharge term $\varphi$ with $\zeta_{0}=0.1, \gamma=1.5$ and $r_{\mathrm{S}}=1$.

\subsection{Sensitivity analysis}

In this section we discuss the effect of changing the frictional and geometrical features of the estuary. Although in principle all the presented methods can be used, in the following we will consider the hybrid model, if not explicitly mentioned.

The relation between the dependent dimensionless parameters (i.e. the damping number $\delta$, the velocity number $\mu$, the celerity number $\lambda$ and the phase lag $\varepsilon$ ) and the friction number $\chi$ for different values of $\varphi$ is shown in Fig. 5 for given values of $\zeta_{0}=0.1, \gamma=1.5$ and $r_{\mathrm{S}}=1$. In general, the river discharge intensifies the effect of friction, i.e. inducing more tidal damping (hence less velocity amplitude and wave celerity). The phase lag $\varepsilon=\arcsin (\mu \lambda)$ increases with increasing $\varphi$ except for small $\chi$ when the values of $\mu \lambda$ are decreased. However, we can see that the curves show an anomaly for very small value of $\chi$. If $\chi$ is very small, the river discharge term in the numerator of the damping Eq. (11) is negligible but becomes important in $\beta$, defined in Eq. (12). For this case, an increase of the river discharge has an opposite effect, particularly on the phase lag. In fact, for the case of a frictionless estuary $(\chi=0)$ the damping Eq. (11) reduces to $\delta=\mu^{2} \gamma \theta /\left(1+\mu^{2} \beta\right)$ in which $\beta$ is decreased with river discharge.

The friction number $\chi$ is also a function of $\zeta$ (see Table 1). In order to illustrate the effect of $\zeta$ we introduce a modified (time-invariant) friction number $\chi_{0}$ as

$\chi_{0}=\chi\left[1-(4 \zeta / 3)^{2}\right] / \zeta=r_{\mathrm{S}} g c_{0} /\left(K^{2} \omega \bar{h}^{4 / 3}\right)$.
Figure 6 describes the effect of the dimensionless tidal amplitude $\zeta$ for given values of $\chi_{0}=20, \gamma=1.5$ and $r_{\mathrm{S}}=1$. Larger $\zeta$ intensifies the effect of river discharge and friction as well, which induces more tidal damping, less velocity amplitude and wave celerity, and increases the phase difference between HW and HWS (or LW and LWS). For small values of $\zeta$, the phase lag decreases with increasing river discharge, also due to the effect on $\beta$.

Figure 7 shows the effect of the estuary shape number $\gamma$ on the main dimensionless parameters for different river discharge conditions $\varphi$ and for given values of the other independent parameters $\left(\zeta_{0}=0.1, \chi_{0}=20\right.$ and $\left.r_{\mathrm{S}}=1\right)$. In general, the damping number $\delta$ and the velocity number $\mu$ decrease with river discharge, which means more tidal damping and less velocity amplitude. On the other hand, the celerity number $\lambda$ is increased (hence slower wave celerity) due to increasing river discharge. For the phase lag $\varepsilon$, we can see from Fig. $7 \mathrm{~d}$ that it decreases with river discharge for small values of $\gamma$ while it increases for larger values of $\gamma$. Cai et al. (2012a) found the same relationship between the main dimensionless parameters and the friction number $\chi$, which confirms our point that including river discharge acts in the same way as increasing the friction.

From an analytical point of view, it is easy to show that the influence of river discharge on the tidal dynamics is very similar to that of the friction number $\chi$. Referring for sake of simplicity to the quasi-nonlinear model, and considering an artificial friction number $\chi_{\mathrm{r}}$ due to river discharge, the 

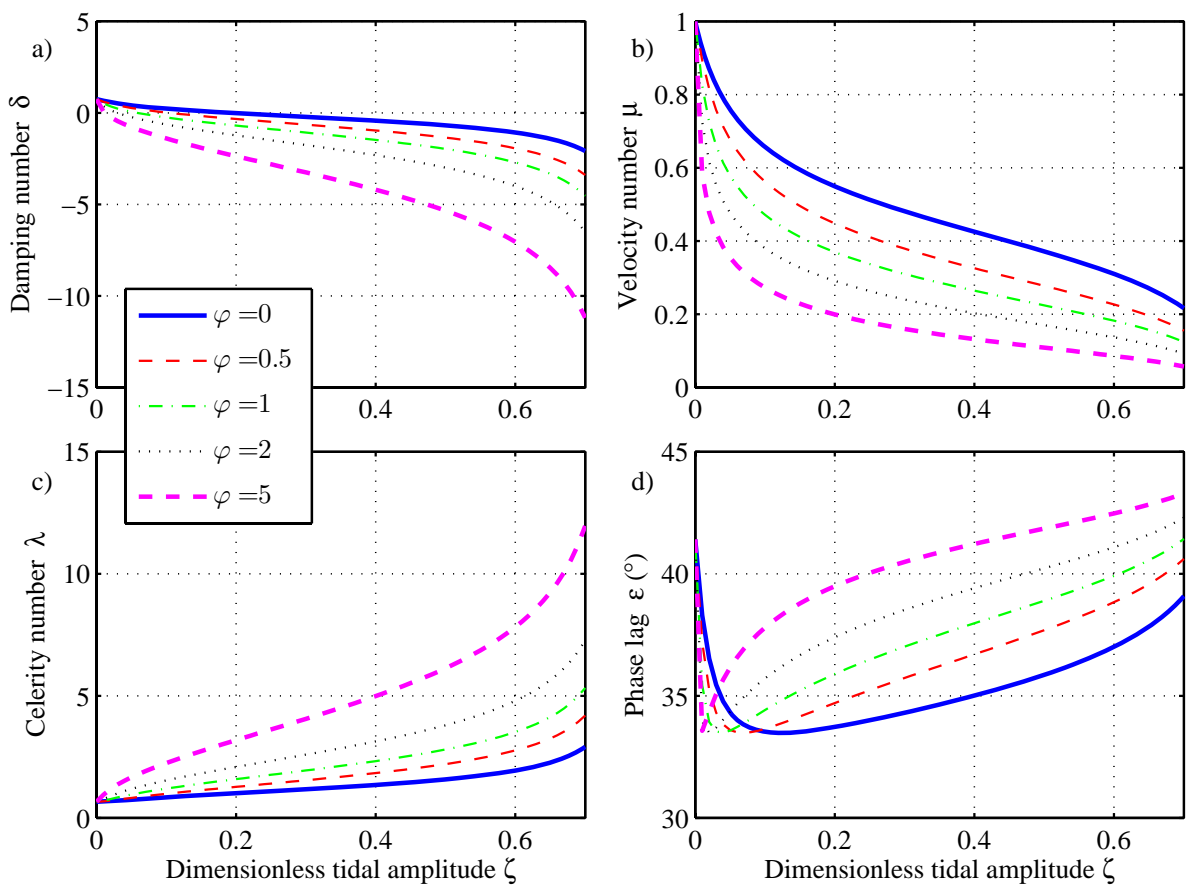

Fig. 6. Relationship between the main dimensionless parameters and the dimensionless tidal amplitude $\zeta$ obtained by solving the Eqs. (11) (with $\Gamma=\Gamma_{\mathrm{H}}$ ), (30) and (31) for different values of the dimensionless river discharge term $\varphi$ with $\chi_{0}=20, \gamma=1.5$ and $r_{\mathrm{S}}=1$, where $\chi_{0}$ is defined with Eq. (36).
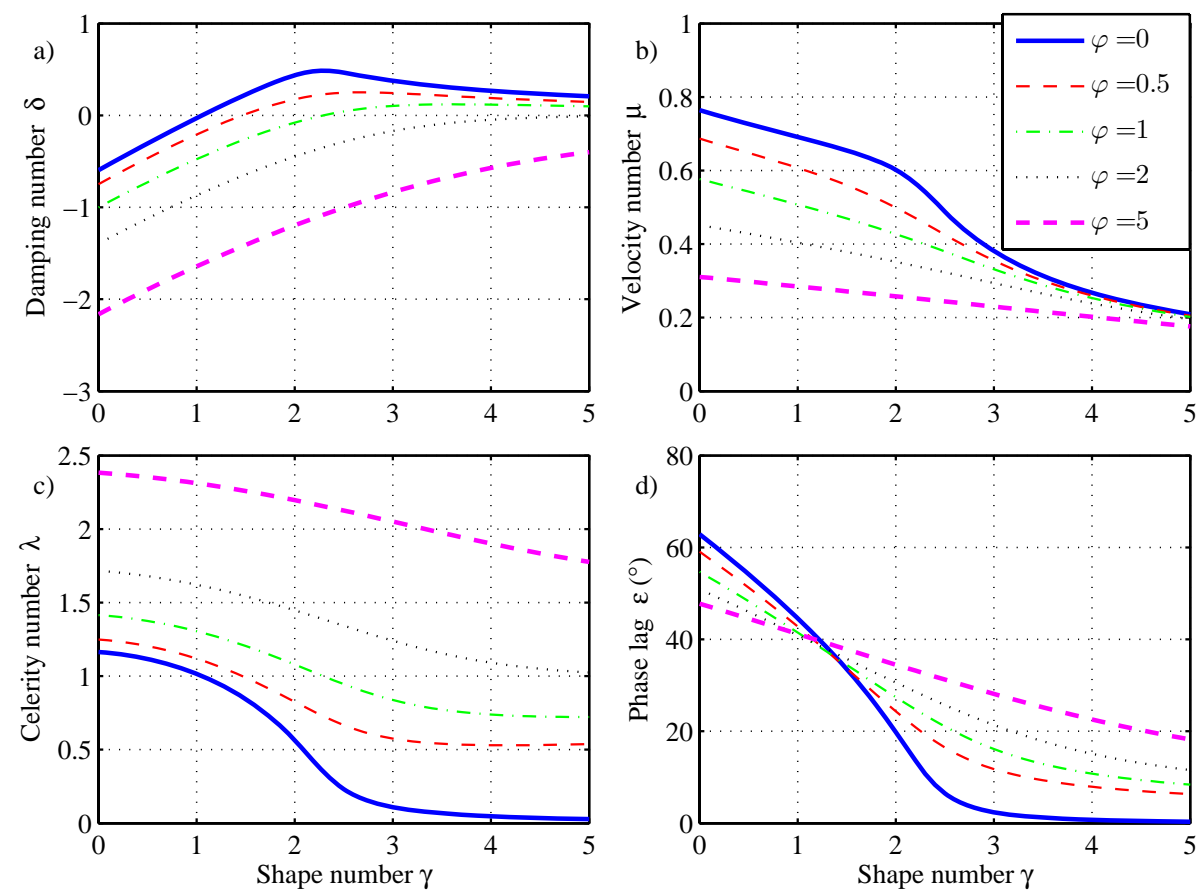

Fig. 7. Relationship between the main dimensionless parameters and the estuary shape number $\gamma$ obtained by solving the Eqs. (11) (with $\left.\Gamma=\Gamma_{\mathrm{H}}\right)$, (30) and (31) for different values of the dimensionless river discharge term $\varphi$ with $\zeta_{0}=0.1, \chi_{0}=20$ and $r_{\mathrm{S}}=1$. 


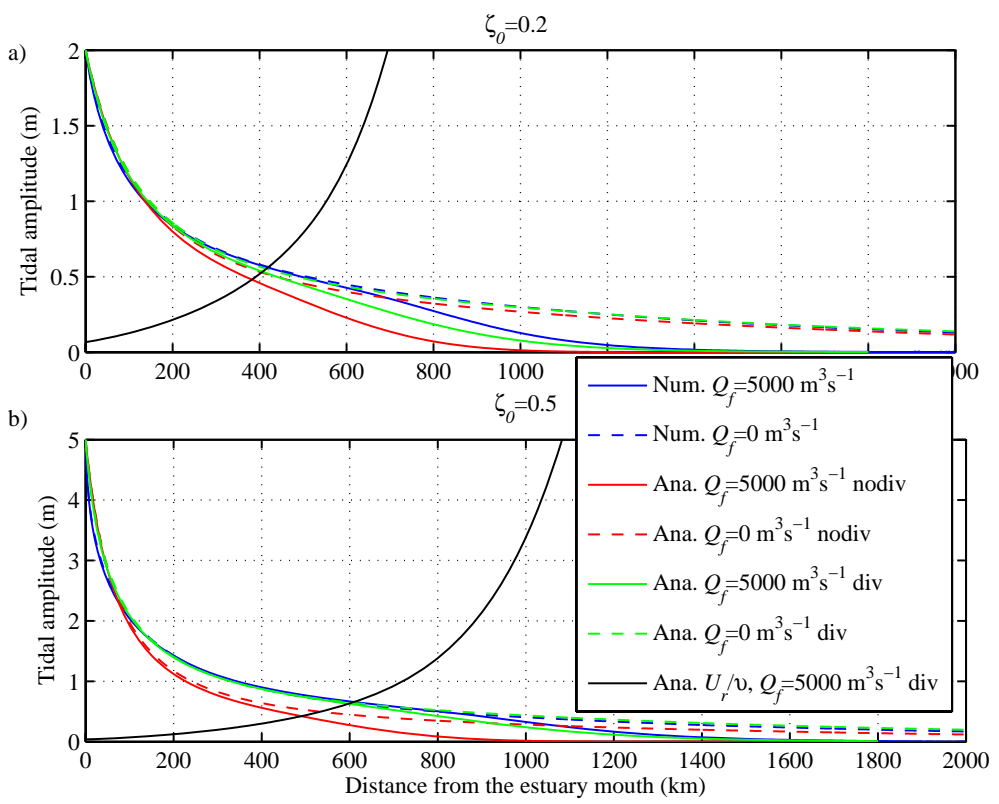

Fig. 8. Comparison between different analytical models and numerical results for given values of $K=60 \mathrm{~m}^{1 / 3} \mathrm{~s}^{-1}, b=352 \mathrm{~km}, \bar{h}=10 \mathrm{~m}$, $\overline{B_{0}}=5000 \mathrm{~m}, \overline{B_{\min }}=300 \mathrm{~m}, \zeta_{0}=0.2$ (a) or $\zeta_{0}=0.5$ (b). The drawn black line represents the river velocity to tide velocity amplitude ratio. The label "nodiv" indicates the models without considering the residual water level slope, while "div" denotes the models accounting for it using the approach described in Sect. 5.

damping Eq. (11) can be written, with Eq. (14) for the case $\varphi<\mu \lambda$, as

$$
\begin{aligned}
\delta & =\frac{\mu^{2}}{1+\mu^{2} \beta}\left[\gamma \theta-(\mu \lambda)^{2} \chi\left(1+\frac{8}{3} \zeta \frac{\varphi}{\mu \lambda}+\left(\frac{\varphi}{\mu \lambda}\right)^{2}\right)\right] \\
& =\frac{\mu^{2}}{1+\mu^{2} \beta}\left[\gamma \theta-(\mu \lambda)^{2} \chi_{\mathrm{r}}\right] .
\end{aligned}
$$

This relationship shows that the effect of river discharge is basically that of increasing friction by a factor that is a function of $\varphi$. Expressing the artificial friction number as $\chi_{\mathrm{r}}=\chi+\Delta \chi_{\mathrm{r}}$ provides an estimation of the correction of the friction term

$$
\frac{\Delta \chi_{\mathrm{r}}}{\chi}=\frac{8}{3} \zeta \frac{\varphi}{\mu \lambda}+\left(\frac{\varphi}{\mu \lambda}\right)^{2}
$$

which is needed to compensate for the lack of considering river discharge. In fact, increasing $\varphi$ is analogous to changing $\chi$, and the expected non-physical adjustment of the Manning-Strickler coefficient $K$ can be estimated for models that do not consider $Q_{\mathrm{f}}$.

\subsection{Comparison with numerical results}

To investigate the performance of the analytical hybrid solutions, the results have been compared with a one-dimensional numerical model. Since we used Eq. (27) to describe the width convergence along the estuary, the estuary shape number accounting for width convergence becomes a function of distance:

$$
\gamma_{\mathrm{b}}=\frac{c_{0}\left(\overline{B_{0}}-\overline{B_{\min }}\right) \exp (-x / b)}{b \omega\left[\overline{B_{\min }}+\left(\overline{B_{0}}-\overline{B_{\min }}\right) \exp (-x / b)\right]} .
$$

When accounting for river discharge, it is necessary to include depth divergence (i.e. the residual water level slope, which is particularly important if the bed is horizontal)

$\gamma_{\mathrm{d}}=-\frac{c_{0}}{\omega} \frac{1}{\bar{h}} \frac{\mathrm{d} \bar{h}}{\mathrm{~d} x}$.

Hence the combined estuary shape number reads

$\gamma=\gamma_{\mathrm{b}}+\gamma_{\mathrm{d}}$

Figure 8 compares the performance of two analytical models, i.e. considering depth divergence (indicated by "div") and without considering depth divergence (denoted by "nodiv"), against the numerical results $\left(Q_{\mathrm{f}}=0\right.$ and $\left.5000 \mathrm{~m}^{3} \mathrm{~s}^{-1}\right)$ for given tidal amplitude to depth ratios at the estuary mouth $\left(\zeta_{0}=0.2\right.$ and $\left.\zeta_{0}=0.5\right)$. We can see from Fig. 8 that the performance of the analytical models is the same in the seaward part, where the effect of river discharge is small compared to tidal flow. Thus the usual assumption that river discharge and residual slope on tidal propagation is negligible in this part of the estuary is reasonable. For the case without river discharge, it can be seen that the analytical model performs 
Table 4. Geometric and flow characteristics of the estuaries studied.

\begin{tabular}{|c|c|c|c|c|c|c|c|}
\hline \multirow[b]{2}{*}{ Estuary } & \multirow[b]{2}{*}{$\begin{array}{l}\text { Reach } \\
(\mathrm{km})\end{array}$} & \multirow[b]{2}{*}{$\begin{array}{l}\text { Depth } \bar{h} \\
(\mathrm{~m})\end{array}$} & \multirow[b]{2}{*}{$\begin{array}{l}\text { Convergence } \\
\text { length } a \\
(\mathrm{~km})\end{array}$} & \multicolumn{2}{|c|}{ Tidal amplitude at the mouth (m) } & \multicolumn{2}{|c|}{ River discharge $Q_{\mathrm{f}}\left(\mathrm{m}^{3} \mathrm{~s}^{-1}\right)$} \\
\hline & & & & Calibration & Verification & Calibration & Verification \\
\hline \multirow{3}{*}{ Modaomen } & $0-43$ & 6.3 & 106 & \multirow{3}{*}{1.31} & \multirow{3}{*}{1.09} & \multirow{3}{*}{2259} & \multirow{3}{*}{2570} \\
\hline & $43-91$ & 7 & infinite & & & & \\
\hline & $91-150$ & 10.3 & 110 & & & & \\
\hline \multirow{3}{*}{ Yangtze } & $0-34$ & 7 & 42 & \multirow{3}{*}{1.8} & \multirow{3}{*}{2.3} & \multirow{3}{*}{13100} & \multirow{3}{*}{17600} \\
\hline & $34-275$ & 9 & 140 & & & & \\
\hline & $275-600$ & 11 & 200 & & & & \\
\hline
\end{tabular}

slightly better when including depth divergence due to residual water level slope, especially in the upper reach of the estuary (this is due to the nonlinearity of the friction term). On the other hand, if river discharge is included, the analytical model requires taking account of depth divergence to accurately simulate the tidal damping. As the tidal amplitude to depth ratio $\zeta$ increases, the numerical simulations indicate that the deviation from the numerical results increases if we neglect the residual slope. Including depth divergence, the analytical model performs much better. However, the correspondence with numerical result is not perfect due to the fact that the analytical model does not account for wave distortion when the tide propagates upstream. More detailed comparion between analytical and fully nonlinear numerical results are presented in the Supplement.

\subsection{Application to real estuaries}

Using the damping Eq. (11) (in the hybrid version, hence $\Gamma=\Gamma_{\mathrm{H}}$ ), the analytical model has been compared to observations made in the Modaomen and Yangtze estuaries in China, where the influence of river discharge in the upstream part is considerable. The Modaomen estuary forms the downstream part of the West River entering the Pearl River Delta, with an annual river discharge of $7115 \mathrm{~m}^{3} \mathrm{~s}^{-1}$ at Makou (Cai et al., 2012b). The Yangtze estuary drains the Yangtze River basin with an annual mean river discharge of $28310 \mathrm{~m}^{3} \mathrm{~s}^{-1}$ at Datong (Zhang et al., 2012).

The computation depends on the three independent variables, i.e. $\gamma, \chi_{0}$ and $\varphi$. Given the flow boundary conditions (i.e. the tidal amplitude at the seaward boundary and river discharge at the landward boundary) and the geometry of the channel, the values of $\gamma, \chi_{0}$ and $\varphi$ can be computed. Hence, the set of four implicit analytical Eqs. (11) (with $\Gamma=\Gamma_{\mathrm{H}}$ ), (28), (29) and (30) can be solved by simple iteration. The tidal amplitude is obtained by numerical integration of the damping number $\delta$ over a length step (e.g. $1 \mathrm{~km}$ ).

Table 4 presents the geometry and flow characteristics (considering two different cases for independent calibration and verification of the model) of the Modaomen and Yangtze on which the computations are based. The convergence
Table 5. Calibrated parameters of the estuaries studied.

\begin{tabular}{|c|c|c|c|c|}
\hline Estuary & $\begin{array}{l}\text { Reach } \\
(\mathrm{km})\end{array}$ & $\begin{array}{l}\text { Storage } \\
\text { width } \\
\text { ratio } \\
r_{S}(-)\end{array}$ & $\begin{array}{c}\text { Manning-Strickler } \\
\text { friction } \\
K\left(\mathrm{~m}^{1 / 3} \mathrm{~s}^{-1}\right) \\
Q_{\mathrm{f}}>0\end{array}$ & $\begin{array}{c}\text { Manning-Strickler } \\
\text { friction } \\
K\left(\mathrm{~m}^{1 / 3} \mathrm{~s}^{-1}\right) \\
Q_{\mathrm{f}}=0\end{array}$ \\
\hline \multirow{3}{*}{ Modaomen } & $0-43$ & 1.5 & 48 & 45 \\
\hline & $43-91$ & 1.4 & 78 & 75 \\
\hline & $91-150$ & 1.3 & 35 & 30 \\
\hline \multirow{3}{*}{ Yangtze } & $0-34$ & 1.8 & 70 & 70 \\
\hline & $34-275$ & 1 & 70 & 70 \\
\hline & $275-600$ & 1 & 45 & 26 \\
\hline
\end{tabular}

length of the cross-sectional area, which is the length scale of the exponential function, is obtained by fitting Eq. (1), where the parallel branches separated by islands are combined, as recommended by Nguyen and Savenije (2006) and Zhang et al. (2012). The calibrated parameters, including the storage width ratio $r_{\mathrm{S}}$ and the Manning-Strickler friction $K$, are presented in Table 5. In general, the storage width ratio $r_{\mathrm{S}}$ ranges between 1 and 2 (Savenije, 2005, 2012). It is noted that a relatively small roughness value of $K=70 \mathrm{~m}^{1 / 3} \mathrm{~s}^{-1}$ (Table 5) was used in the Yangtze estuary, which is due to the fact that it is a silt-mud estuary, while the bed consists of sands in the Modaomen estuary. The reason for the small roughness value of $K=78 \mathrm{~m}^{1 / 3} \mathrm{~s}^{-1}$ used in the middle reach of the Modaomen estuary (43-91 km) is probably due to the effect of parallel branches (see Cai et al., 2012b).

Figure 9 shows the longitudinal computation of the tidal amplitude, the travel time (both at HW and LW) and damping number applied to the Modaomen estuary. Observations of tidal amplitude and travel time of the tidal wave on 8 9 February 2001 were used to calibrate the model, while the observed data on 5-6 December 2002 were used for verification. Both the model with river discharge and the model without river discharge can be made to fit the observations if a suitable friction coefficient is used, as discussed in the previous section. However, such calibrations yield significantly lower values of the Manning-Strickler coefficients upstream. For the model without river discharge we would have required an unrealistically low Manning-Strickler value 

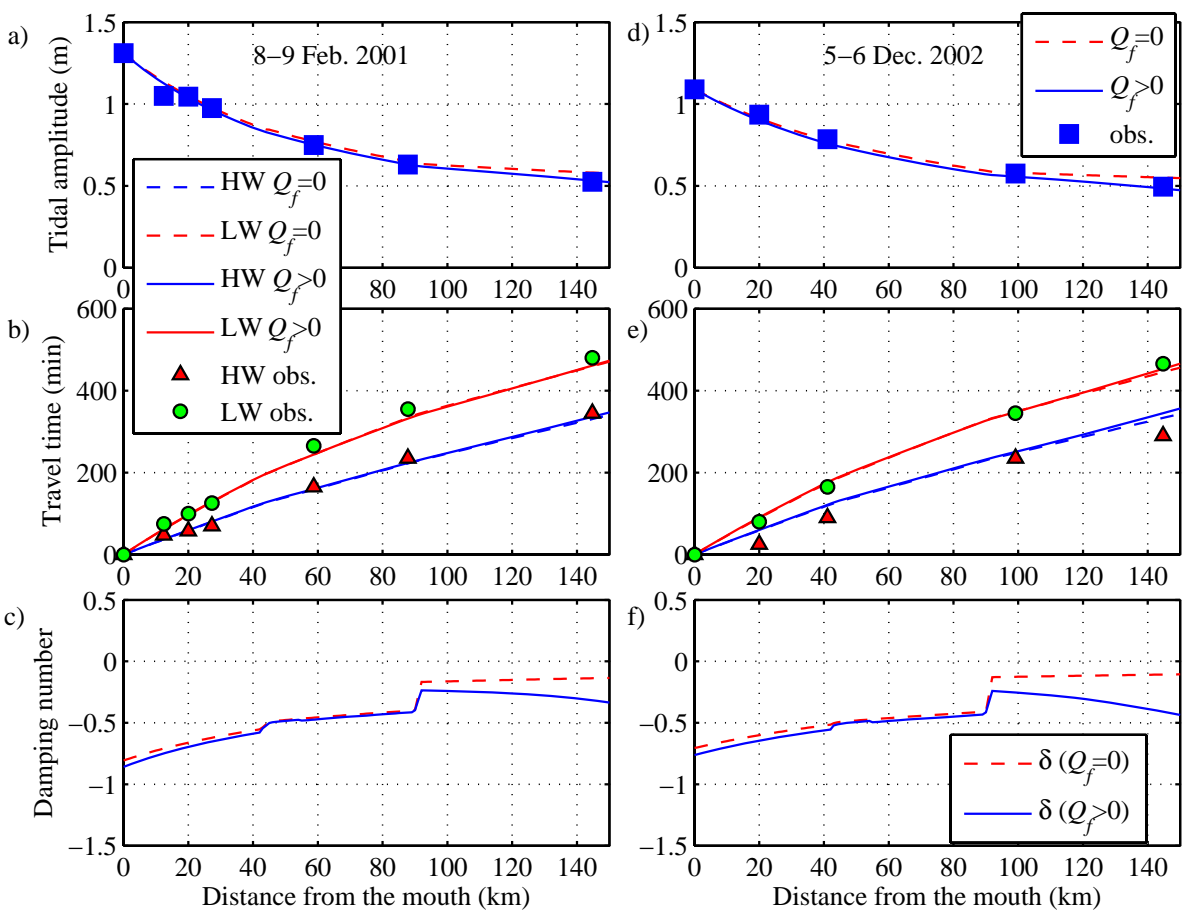

Fig. 9. Comparison of analytically calculated tidal amplitude (a, d), travel time (b, e) with measurements and comparison of two analytical models to compute the dimensionless damping number (c, f) on 8-9 February 2001 (calibration) and 5-6 December 2002 (validation) in the Modaomen estuary. The dashed line represents the model where river discharge is neglected. The continuous line represents the model accounting for the effect of river discharge. Both models used the same friction coefficients calibrated while considering river discharge.

of $K=30 \mathrm{~m}^{1 / 3} \mathrm{~s}^{-1}$ to fit the data in the upstream part of Modaomen estuary $(91-150 \mathrm{~km})$. In Fig. 9, the new model accounting for the effect of river discharge is compared to the original model with the same roughness, but without river discharge. In the lower part of the estuary the models behave the same (e.g. see the dimensionless damping number in Fig. 9c and f), but behave differently in the upper reach where the river discharge is dominant. Without considering river discharge, the model underestimates tidal damping upstream.

In Fig. 10, we can see that the analytically calculated tidal amplitude in the Yangtze estuary is in good correspondence with the observed data on 21-22 December 2006 (calibration) and 18-19 February 2003 (verification). For the travel time, the correspondence with observations at HW is very good, but the correspondence for LW shows a big deviation from the measurements, with an underestimation of the celerity for LW. The reason for the deviation should probably be attributed to significant tidal wave distortion due to the strong river discharge, which is critical for the assumption that the celerities at HW and LW times are symmetrical compared with the tidal average wave celerity (see Eq. A8 in Appendix A). Without considering the river discharge, a much higher and unrealistic roughness (implying a lower value of $K=26 \mathrm{~m}^{1 / 3} \mathrm{~s}^{-1}$ ) would be necessary in the upstream part of the estuary $(275-600 \mathrm{~km})$ to compensate the influence of river discharge.

\section{Conclusions}

In this paper, we have extended the analytical framework for tidal hydrodynamics proposed by Cai et al. (2012a) by taking account of river discharge. With the envelope method (Savenije, 1998), different friction formulations considering river discharge can be used to derive expressions for the envelopes at HW and LW and subsequently to arrive at the corresponding damping equations. When combined with the phase lag equation, the scaling equation and the celerity equation, these damping equations can be iteratively solved for the dimensionless parameters $\mu, \delta, \lambda$ and $\varepsilon$, which are related to tidal velocity amplitude, tidal damping, wave celerity, and phase lag, respectively. Thus, for given topography, friction, tidal amplitude at the seaward boundary and river discharge at the landward boundary, we can reproduce the main tidal dynamics along the estuary.

Unlike previous studies (e.g. Godin, 1985, 1999) that neglect higher-order term, the envelope method retains all terms although it still requires a small tidal amplitude to depth ratio. This allows for including river discharge in a fully analytical framework. It is also worth recognizing that the friction term has two nonlinear sources, the quadratic velocity $U|U|$, and the variation of the hydraulic radius (approximated by the flow depth $h$ ) in the denominator (Parker, 1991). Lorentz's friction formulations disregarded the tidally 

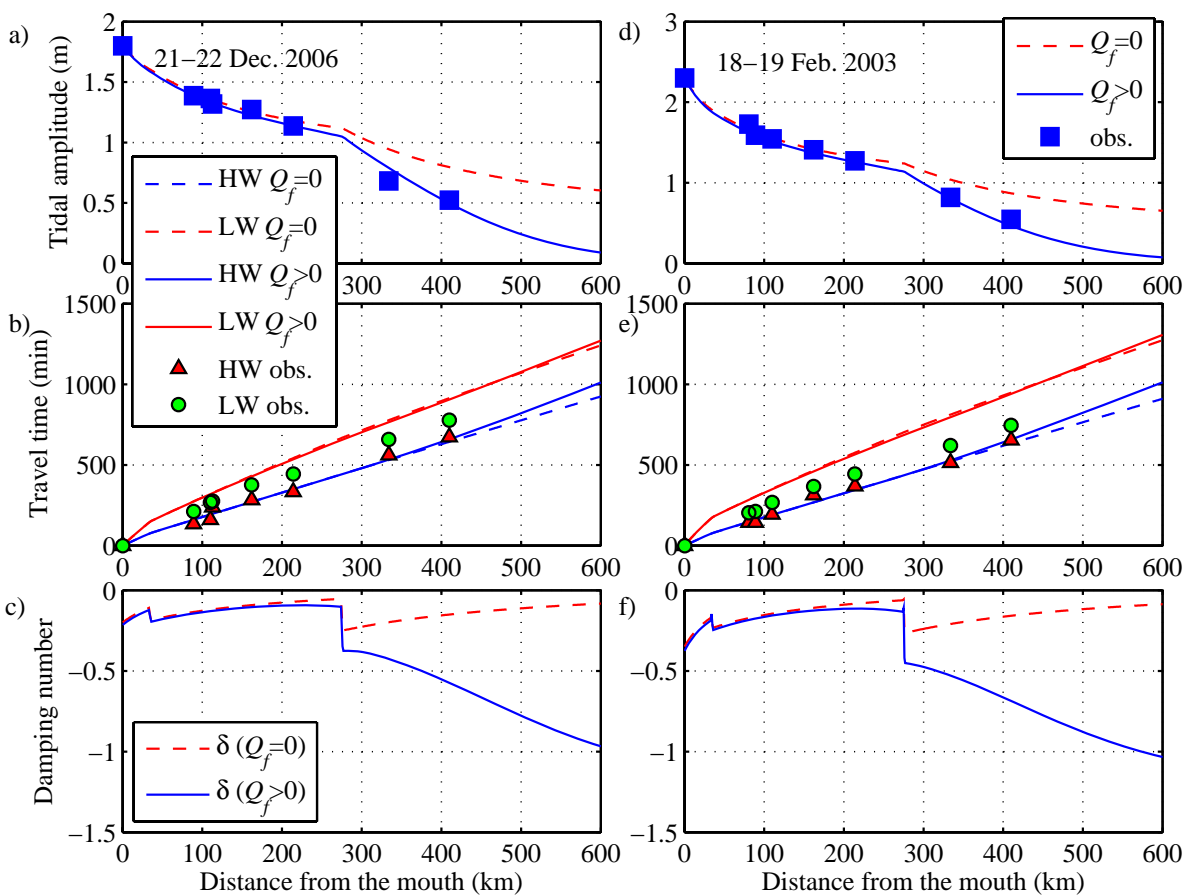

Fig. 10. Comparison of analytically calculated tidal amplitude (a, d), travel time (b, e) with measurements and comparison of two analytical models to compute the dimensionless damping number (c, f) on 21-22 December 2006 (calibration) and 18-19 February 2003 (validation) in the Yangtze estuary. The dashed line represents the model where river discharge is neglected. The continuous line represents the model accounting for the effect of river discharge. Both models used the same friction coefficients calibrated while considering river discharge.

varying depth and only focus on the quadratic velocity. By using the envelope method, we are able to take this second nonlinear source into account and end up with a more complete damping equation accounting for river discharge.

We also note that the averaged water level tends to rise landward and that this effect has a considerable influence on tidal wave propagation, particularly when accounting for the effect of river discharge, since river discharge affects depth convergence and friction at the same time. An iterative analytical method has been proposed to include the residual water level slope into the analysis, which significantly improved the performance of the analytical model.

With respect to e.g. Cai et al. (2012a), where we did not consider the effect of river discharge, this method is an improvement that is important especially in the upstream part of the estuary where the influence of river discharge is considerable. This is clearly demonstrated by the application of the analytical model to two real estuaries (Modaomen and Yangtze in China), which shows that the proposed model fits the observations with realistic roughness value in the upstream part, while the model without considering river discharge can only be fitted with unrealistically high roughness values.

\section{Appendix A}

Derivation of Lorentz's damping equation incorporating river discharge using the envelope method

Using a Lagrangean approach as in Savenije (2005, 2012), the continuity equation can be written as

$$
\frac{\mathrm{d} V}{\mathrm{~d} t}=r_{\mathrm{s}} \frac{c}{h} \frac{\mathrm{d} h}{\mathrm{~d} t}-\frac{c V}{b}+c V \frac{1}{\eta} \frac{\mathrm{d} \eta}{\mathrm{d} x} .
$$

The momentum equation can also be written in a Lagrangean form, yielding

$$
\frac{\mathrm{d} V}{\mathrm{~d} t}+g \frac{\partial h}{\partial x}+g\left(I_{\mathrm{b}}-I_{\mathrm{r}}\right)+g \frac{V|V|}{K^{2} h^{4 / 3}}=0,
$$

where $I_{\mathrm{b}}$ is the bottom slope and $I_{\mathrm{r}}$ is the water level residual slope resulting from the density gradient. Combination of these equations, and using $V=\mathrm{d} x / \mathrm{d} t$, yields

$r_{\mathrm{s}} \frac{c V}{g h} \frac{\mathrm{d} h}{\mathrm{~d} x}-\frac{c V}{g}\left(\frac{1}{b}-\frac{1}{\eta} \frac{\mathrm{d} \eta}{\mathrm{d} x}\right)+\frac{\partial h}{\partial x}+I_{\mathrm{b}}-I_{\mathrm{r}}+\frac{V|V|}{K^{2} h^{4 / 3}}=0$.

Next, we condition Eq. (A3) for the situation of high water (HW) and low water (LW). The following relations apply to $h_{\mathrm{HW}}$ and $h_{\mathrm{LW}}$ : 


$$
\begin{aligned}
& \frac{\mathrm{d} h_{\mathrm{HW}}}{\mathrm{d} x}-\frac{\mathrm{d} h_{\mathrm{LW}}}{\mathrm{d} x}=2 \frac{\mathrm{d} \eta}{\mathrm{d} x}, \\
& \frac{\mathrm{d} h_{\mathrm{HW}, \mathrm{LW}}}{\mathrm{d} x}=\left.\frac{\partial h}{\partial x}\right|_{\mathrm{HW}, \mathrm{LW}}, \\
& \frac{\mathrm{d} h_{\mathrm{HW}}}{\mathrm{d} x}+\frac{\mathrm{d} h_{\mathrm{LW}}}{\mathrm{d} x} \approx 2 \frac{\mathrm{d} \bar{h}}{\mathrm{~d} x},
\end{aligned}
$$

with $h_{\mathrm{HW}} \approx \bar{h}+\eta$ and $h_{\mathrm{LW}} \approx \bar{h}-\eta$. These three equations are acceptable if $\eta / \bar{h} \ll 1$.

The tidal velocities at HW and LW the following expressions can be expressed as

$V_{\mathrm{HW}} \approx v \sin (\varepsilon)-U_{\mathrm{r}}, \quad V_{\mathrm{LW}} \approx-v \sin (\varepsilon)-U_{\mathrm{r}}$,

where the river flow velocity $U_{\mathrm{r}}$ is negative (it is in ebb direction). Further we assume that wave celerity is proportional to the square root of the depth:

$\frac{c_{\mathrm{HW}}}{\sqrt{h_{\mathrm{HW}}}} \approx \frac{c_{\mathrm{LW}}}{\sqrt{h_{\mathrm{LW}}}} \approx \frac{c}{\sqrt{\bar{h}}}$.

In this example we use Lorentz's linearization Eq. (21) of the bed friction (Lorentz, 1926), but also take into account the effect of the periodic variation of the hydraulic radius in the denominator of the friction term (i.e. $K^{2} h^{4 / 3}$ ). Combination of Eqs. (A3), (A5), and the first of Eq. (A7) yields the following envelope for $\mathrm{HW}$ :

$$
\begin{gathered}
\frac{r_{\mathrm{S}} c_{\mathrm{HW}}\left[v \sin (\varepsilon)-U_{\mathrm{r}}\right]}{g(\bar{h}+\eta)} \frac{\mathrm{d} h_{\mathrm{HW}}}{\mathrm{d} x}-\frac{c_{\mathrm{HW}}\left[v \sin (\varepsilon)-U_{\mathrm{r}}\right]}{g} \\
\left(\frac{1}{b}-\frac{1}{\eta} \frac{\mathrm{d} \eta}{\mathrm{d} x}\right)+\frac{\mathrm{d} h_{\mathrm{HW}}}{\mathrm{d} x}+\frac{1}{K^{2}(\bar{h}+\kappa \eta)^{4 / 3}} \\
{\left[\frac{1}{4} L_{0} v^{2}+\frac{1}{2} L_{1} v^{2} \sin (\varepsilon)\right]=-I_{\mathrm{b}}+I_{\mathrm{r}},}
\end{gathered}
$$

where $\kappa=1$ corresponds to the time-dependent case, while $\kappa=0$ to the time-independent case. Similarly, for LW, combination of Eqs. (A3), (A5), and the second of Eq. (A7) yields the LW envelope:

$$
\begin{gathered}
-\frac{r_{\mathrm{S}} c_{\mathrm{LW}}\left[v \sin (\varepsilon)+U_{\mathrm{r}}\right]}{g(\bar{h}-\eta)} \frac{\mathrm{d} h_{\mathrm{LW}}}{\mathrm{d} x}+\frac{c_{\mathrm{LW}}\left[v \sin (\varepsilon)+U_{\mathrm{r}}\right]}{g} \\
\left(\frac{1}{b}-\frac{1}{\eta} \frac{\mathrm{d} \eta}{\mathrm{d} x}\right)+\frac{\mathrm{d} h_{\mathrm{LW}}}{\mathrm{d} x}+\frac{1}{K^{2}(\bar{h}-\kappa \eta)^{4 / 3}} \\
{\left[\frac{1}{4} L_{0} v^{2}-\frac{1}{2} L_{1} v^{2} \sin (\varepsilon)\right]=-I_{\mathrm{b}}+I_{\mathrm{r}} .}
\end{gathered}
$$

Subtraction of these envelopes, using a Taylor series expansion of $h^{4 / 3}$, and taking into account the assumption on the wave celerity yields the following expressions:

$$
\begin{aligned}
& \frac{r_{\mathrm{S}} c v \sin (\varepsilon)}{\bar{h}}\left(\frac{1}{\sqrt{1+\zeta}} \frac{\mathrm{d} h_{\mathrm{HW}}}{\mathrm{d} x}+\frac{1}{\sqrt{1-\zeta}} \frac{\mathrm{d} h_{\mathrm{LW}}}{\mathrm{d} x}\right) \\
& -\frac{r_{\mathrm{S}} c U_{\mathrm{r}}}{\bar{h}}\left(\frac{1}{\sqrt{1+\zeta}} \frac{\mathrm{d} h_{\mathrm{HW}}}{\mathrm{d} x}-\frac{1}{\sqrt{1-\zeta}} \frac{\mathrm{d} h_{\mathrm{LW}}}{\mathrm{d} x}\right) \\
& -\left[2 c v \sin (\varepsilon)+2 c U_{\mathrm{r}}(1-\sqrt{1+\zeta})\right]\left(\frac{1}{b}-\frac{1}{\eta} \frac{\mathrm{d} \eta}{\mathrm{d} x}\right) \\
& +2 g \frac{\mathrm{d} \eta}{\mathrm{d} x}+f^{\prime}\left[\frac{L_{1} v^{2} \sin (\varepsilon)}{\bar{h}}-\kappa \frac{2 L_{0} v^{2} \zeta}{\overline{3 h}}\right]=0,
\end{aligned}
$$

with the dimensionless friction factor $f^{\prime}$ defined as

$$
f^{\prime}=g /\left(K^{2} \bar{h}^{1 / 3}\right)\left[1-(\kappa 4 \zeta / 3)^{2}\right]^{-1} .
$$

The parts between brackets in the first and second terms of Eq. (A11) can be replaced by the residual water level slope $\mathrm{d} \bar{h} / \mathrm{d} x$ defined in Eq. (A6) and $\mathrm{d} \bar{h} / \mathrm{d} x$ defined in Eq. (A4), respectively, provided $\zeta \ll 1$. Elaboration yields

$$
\begin{gathered}
\frac{1}{\eta} \frac{\mathrm{d} \eta}{\mathrm{d} x}\left(\theta-r_{\mathrm{s}} \frac{\varphi}{\sin (\varepsilon)} \zeta+\frac{g \eta}{c v \sin (\varepsilon)}\right)=\frac{\theta}{b}-r_{\mathrm{s}} \frac{1}{\bar{h}} \frac{\mathrm{d} \bar{h}}{\mathrm{~d} x} \\
-\frac{L_{1}}{2} f^{\prime} \frac{v}{\bar{h} c+\kappa \frac{L_{0}}{3} f^{\prime} \frac{v \zeta}{\bar{h} c} \frac{1}{\sin (\varepsilon)} .}
\end{gathered}
$$

The dimensionless parameters $\varphi$ and $\theta$ have been defined in the main text. The first two terms on the right-hand side of Eq. (A13) represent the width and depth convergences and can be written as

$\frac{\theta}{b}-r_{\mathrm{S}} \frac{1}{\bar{h}} \frac{\mathrm{d} \bar{h}}{\mathrm{~d} x}=\frac{\theta}{b}+\frac{r_{\mathrm{S}}}{d} \approx \frac{\theta}{a}$.

Here, it has been assumed that both $\theta$ and $r_{\mathrm{S}}$ are close to unity. Substitution of Eq. (A14) into Eq. (A13) yields

$$
\begin{gathered}
\frac{1}{\eta} \frac{\mathrm{d} \eta}{\mathrm{d} x}\left(\theta-r_{\mathrm{s}} \frac{\varphi}{\sin (\varepsilon)} \zeta+\frac{g \eta}{c v \sin (\varepsilon)}\right)=\frac{\theta}{a}-\frac{L_{1}}{2} \\
f^{\prime} \frac{v}{\bar{h} c}+\kappa \frac{L_{0}}{3} f^{\prime} \frac{v \zeta}{\bar{h} c} \frac{1}{\sin (\varepsilon)} .
\end{gathered}
$$

Making use of the dimensionless parameters and adopting the scaling equation $\sin (\varepsilon)=\mu \lambda$, Eq. (A15) reduces to the following expression:

$$
\begin{aligned}
\delta= & \frac{\mu^{2}}{1+\mu^{2}\left[\theta-r_{\mathrm{s}} \varphi \zeta /(\mu \lambda)\right]} \\
& {\left[\gamma \theta-\chi\left(\frac{1}{2} L_{1} \mu \lambda-\kappa \frac{1}{3} L_{0} \zeta\right)\right], }
\end{aligned}
$$

or

$$
\delta=\frac{\mu^{2}}{1+\mu^{2} \beta}\left(\gamma \theta-\chi \mu \lambda \Gamma_{\mathrm{L}}\right), \quad \Gamma_{\mathrm{L}}=\frac{L_{1}}{2}-\kappa \zeta \frac{L_{0}}{3 \mu \lambda} .
$$




\section{Appendix B}

\section{Derivation of the mean free surface elevation due to nonlinear frictional effect}

Integration of the Lagrangean momentum equation (Eq. A2) over a tidal period leads to

$V(t+T)-V(t)+g \frac{\partial}{\partial x} \int_{t}^{t+T} z \mathrm{~d} \sigma+g_{t}^{t+T} \frac{V|V|}{K^{2} h^{4 / 3}} \mathrm{~d} \sigma=0$,

which can be simplified as

$\frac{\partial \bar{z}}{\partial x}=-\overline{\frac{V|V|}{K^{2} h^{4 / 3}}}$,

when tidally averaged conditions achieve a regime configuration. Making use of the boundary condition $\bar{z}=0$ at $x=0$, integration of Eq. (B2) yields an expression for the mean free surface elevation:

$\bar{z}(x)=-\int_{0}^{x} \overline{\frac{V|V|}{K^{2} h^{4 / 3}}} \mathrm{~d} x$.

Table A1. Nomenclature.

\begin{tabular}{|c|c|}
\hline \multicolumn{2}{|c|}{ The following symbols are used in this paper } \\
\hline$a$ & convergence length of cross-sectional area; \\
\hline $\bar{A}$ & tidally averaged cross-sectional area of flow; \\
\hline$\overline{A_{0}}$ & $\begin{array}{l}\text { tidally averaged cross-sectional area at the } \\
\text { estuary mouth; }\end{array}$ \\
\hline$b$ & convergence length of width; \\
\hline $\bar{B}$ & tidally averaged stream width; \\
\hline$\overline{B_{0}}$ & tidally averaged width at the estuary mouth; \\
\hline$B_{\mathrm{S}}$ & storage width; \\
\hline$c$ & wave celerity; \\
\hline$c_{0}$ & $\begin{array}{l}\text { celerity of a frictionless wave in a } \\
\text { prismatic channel; }\end{array}$ \\
\hline$c_{\mathrm{HW}}$ & wave celerity at $\mathrm{HW}$ \\
\hline$c_{\mathrm{LW}}$ & wave celerity at $\mathrm{LW}$; \\
\hline$d$ & convergence length of depth; \\
\hline$f$ & $\begin{array}{l}\text { friction factor accounting for the difference } \\
\text { in friction at } \mathrm{HW} \text { and } \mathrm{LW} \text {; }\end{array}$ \\
\hline$f_{0}$ & $\begin{array}{l}\text { friction factor without considering the } \\
\text { difference in friction at HW and LW; }\end{array}$ \\
\hline$F$ & quadratic friction term; \\
\hline$F_{\mathrm{D}}$ & $\begin{array}{l}\text { Dronkers' friction term accounting for } \\
\text { river discharge; }\end{array}$ \\
\hline$F_{\mathrm{G}}$ & $\begin{array}{l}\text { Godin's friction term accounting for } \\
\text { river discharge; }\end{array}$ \\
\hline
\end{tabular}

Table A1. Continued.

\begin{tabular}{|c|c|}
\hline \multicolumn{2}{|c|}{ The following symbols are used in this paper } \\
\hline$F_{\mathrm{H}}$ & $\begin{array}{l}\text { hybrid friction term accounting for } \\
\text { river discharge; }\end{array}$ \\
\hline$F_{\mathrm{L}}$ & $\begin{array}{l}\text { Lorentz's friction term accounting for } \\
\text { river discharge; }\end{array}$ \\
\hline$g$ & acceleration due to gravity; \\
\hline$G_{0}, G_{1}, G_{2}, G_{3}$ & $\begin{array}{l}\text { Godin's coefficients accounting for } \\
\text { river discharge; }\end{array}$ \\
\hline$h$ & cross-sectional average depth; \\
\hline $\bar{h}$ & tidal average depth; \\
\hline$\overline{h_{0}}$ & $\begin{array}{l}\text { tidally averaged depth at the estuary } \\
\text { mouth; }\end{array}$ \\
\hline$h_{\mathrm{HW}}$ & depth at HW; \\
\hline$h_{\mathrm{LW}}$ & depth at LW; \\
\hline$I_{\mathrm{b}}$ & bottom slope; \\
\hline$I_{\mathrm{r}}$ & $\begin{array}{l}\text { water level residual slope due to the } \\
\text { density gradient; }\end{array}$ \\
\hline$K$ & Manning-Strickler friction factor; \\
\hline$L_{0}, L_{1}$ & $\begin{array}{l}\text { Lorentz's coefficients accounting for } \\
\text { river discharge; }\end{array}$ \\
\hline$p_{0}, p_{1}, p_{2}, p_{3}$ & $\begin{array}{l}\text { Chebyschev coefficients accounting for } \\
\text { river discharge; }\end{array}$ \\
\hline$Q_{\mathrm{f}}$ & river discharge; \\
\hline$r_{\mathrm{s}}$ & storage width ratio; \\
\hline$t$ & time; \\
\hline$T$ & tidal period; \\
\hline$U$ & cross-sectional average flow velocity; \\
\hline$U_{\mathrm{t}}$ & tidal velocity; \\
\hline$U_{\mathrm{r}}$ & river velocity; \\
\hline$U^{\prime}$ & $\begin{array}{l}\text { the maximum possible velocity in } \\
\text { Godin's approach; }\end{array}$ \\
\hline$V_{\mathrm{HW}}$ & velocity at $\mathrm{HW}$ \\
\hline$V_{\mathrm{LW}}$ & velocity at LW; \\
\hline$V$ & Lagrangean velocity for a moving particle; \\
\hline$x$ & distance from the estuary mouth; \\
\hline$z$ & free surface elevation; \\
\hline$\alpha, \beta$ & $\begin{array}{l}\text { functions of dimensionless river discharge } \\
\text { term } \varphi \text {; }\end{array}$ \\
\hline$\gamma$ & estuary shape number; \\
\hline$\gamma_{\mathrm{b}}$ & $\begin{array}{l}\text { estuary shape number accounting for } \\
\text { width convergence; }\end{array}$ \\
\hline$\gamma_{\mathrm{d}}$ & $\begin{array}{l}\text { estuary shape number accounting for } \\
\text { depth convergence; }\end{array}$ \\
\hline$\Gamma$ & $\begin{array}{l}\text { damping parameter of quasi-nonlinear } \\
\text { model; }\end{array}$ \\
\hline$\Gamma_{\mathrm{L}}$ & damping parameter of linear model; \\
\hline
\end{tabular}


Table A1. Continued.

\begin{tabular}{|c|c|}
\hline \multicolumn{2}{|c|}{ The following symbols are used in this paper } \\
\hline$\Gamma_{\mathrm{D}}$ & damping parameter of Dronkers' model; \\
\hline$\Gamma_{\mathrm{G}}$ & damping parameter of Godin's model; \\
\hline$\Gamma_{\mathrm{H}}$ & damping parameter of hybrid model; \\
\hline$\delta$ & damping number; \\
\hline$\varepsilon$ & phase lag between HW and HWS (or LW and LWS); \\
\hline$\zeta$ & tidal amplitude to depth ratio; \\
\hline$\eta$ & tidal amplitude; \\
\hline$\eta_{0}$ & tidal amplitude at the estuary mouth; \\
\hline$\theta$ & $\begin{array}{l}\text { dimensionless term accounting for wave celerity } \\
\text { not being equal at } \mathrm{HW} \text { and } \mathrm{LW} \text {; }\end{array}$ \\
\hline$\kappa$ & $\begin{array}{l}\text { coefficient that include the effect of time-dependent } \\
\text { depth in the friction term; }\end{array}$ \\
\hline$\lambda$ & celerity number; \\
\hline$\mu$ & velocity number; \\
\hline$\rho$ & water density; \\
\hline$v$ & tidal velocity amplitude; \\
\hline$\phi_{z}, \phi_{U}$ & phase of water level and velocity; \\
\hline$\varphi$ & $\begin{array}{l}\text { dimensionless river discharge term accounting for } \\
\text { river discharge; }\end{array}$ \\
\hline$\chi$ & friction number; \\
\hline$\chi_{0}$ & time-invariant friction number; \\
\hline$\omega$ & tidal frequency. \\
\hline
\end{tabular}

\section{Supplementary material related to this article is available online at http://www.hydrol-earth-syst-sci.net/ 18/287/2014/hess-18-287-2014-supplement.pdf.}

Acknowledgements. The authors would like to thank the two anonymous referees for their valuable comments and suggestions, which have greatly improved this paper. The first author is financially supported for his Ph.D. research by the China Scholarship Council with the project reference number of 2010638037.

Edited by: A. D. Reeves

\section{References}

Cai, H., Savenije, H. H. G., and Toffolon, M.: A new analytical framework for assessing the effect of sea-level rise and dredging on tidal damping in estuaries, J. Geophys. Res., 117, C09023, doi:10.1029/2012JC008000, 2012a.

Cai, H., Savenije, H. H. G., Yang, Q., Ou, S., and Lei, Y.: Influence of river discharge and dredging on tidal wave propagation; Modaomen estuary case, J. Hydraul. Eng., 138, 885-896, doi:10.1061/(ASCE)HY.1943-7900.0000594, 2012b.

Dronkers, J. J.: Tidal computations in River and Coastal Waters, Elsevier, New York, 1964.
Friedrichs, C. T. and Aubrey, D. G.: Tidal Propagation in Strongly Convergent Channels, J. Geophys. Res., 99, 3321-3336, 1994.

Godin, G.: Modification of River Tides by the Discharge, J. Waterw. Port C-ASCE, 111, 257-274, 1985.

Godin, G.: Compact Approximations to the Bottom Friction Term, for the Study of Tides Propagating in Channels, Cont. Shelf Res. 11, 579-589, 1991.

Godin, G.: The propagation of tides up rivers with special considerations on the upper Saint Lawrence river, Estuar. Coast. Shelf. S., 48, 307-324, 1999.

Horrevoets, A. C., Savenije, H. H. G., Schuurman, J. N., and Graas, S.: The influence of river discharge on tidal damping in alluvial estuaries, J. Hydrol., 294, 213-228, 2004.

Hunt, J. N.: Tidal oscillations in estuaries, Geo. J. Roy. Ast. Soc., 8, 440-455, doi:10.1111/j.1365-246X.1964.tb03863.x, 1964.

Ippen, A. T.: Tidal dynamics in estuaries, part I: Estuaries of rectangular section, in: Estuary and Coastline Hydrodynamics, edited by: Ippen, A. T., McGraw-Hill, New York, 1966.

Jay, D. A.: Green Law Revisited - Tidal Long-Wave Propagation in Channels with Strong Topography, J. Geophys. Res., 96, 2058520598, 1991

Jay, D. A., Leffler, K., and Degens, S.: Long-Term Evolution of Columbia River Tides, J. Waterw. Port C-ASCE, 137, 182-191, 2011.

Kukulka, T. and Jay, D. A.: Impacts of Columbia River discharge on salmonid habitat: 1. A nonstationary fluvial tide model, J. Geophys. Res., 108, 3293, doi:10.1029/2002JC001382, 2003.

Lanzoni, S. and Seminara, G.: On tide propagation in convergent estuaries, J. Geophys. Res., 103, 30793-30812, 1998.

Leblond, P. H.: Tidal Propagation in Shallow Rivers, J. Geophys Res., 83, 4717-4721, 1978.

Lorentz, H. A.: Verslag Staatscommissie Zuiderzee, Algemene Landsdrukkerij, The Hague, the Netherlands, 1926.

Nguyen, A. D. and Savenije, H. H. : Salt intrusion in multi-channel estuaries: a case study in the Mekong Delta, Vietnam, Hydrol. Earth Syst. Sci., 10, 743-754, doi:10.5194/hess-10-743-2006, 2006

Parker, B. B.: The relative importance of the various nonlinear mechanisms in a wide range of tidal interactions, in: Tidal Hydrodynamics, edited by: Parker, B. B., John Wiley, New York, 236-268, 1991.

Prandle, D.: Relationships between tidal dynamics and bathymetry in strongly convergent estuaries, J. Phys. Oceanogr., 33, 27382750, 2003.

Savenije, H. H. G.: Lagrangian Solution of St Venants Equations for Alluvial Estuary, J. Hydraul. Eng., 118, 1153-1163, 1992.

Savenije, H. H. G.: Determination of Estuary Parameters on Basis of Lagrangian Analysis, J. Hydraul. Eng., 119, 628-642, 1993.

Savenije, H. H. G.: Analytical expression for tidal damping in alluvial estuaries, J. Hydraul. Eng., 124, 615-618, 1998.

Savenije, H. H. G.: A simple analytical expression to describe tidal damping or amplification, J. Hydrol., 243, 205-215, 2001.

Savenije, H. H. G.: Salinity and Tides in Alluvial Estuaries, Elsevier, New York, 2005.

Savenije, H. H. G.: Salinity and Tides in Alluvial Estuaries, completely revised 2nd Edn., www.salinityandtides.com (last access: 26 June 2013), 2012. 
Savenije, H. H. G. and Veling, E. J. M.: Relation between tidal damping and wave celerity in estuaries, J. Geophys. Res., 110, C04007, doi:10.1029/2004JC002278, 2005.

Savenije, H. H. G., Toffolon, M., Haas, J., and Veling, E. J. M.: Analytical description of tidal dynamics in convergent estuaries, J. Geophys. Res., 113, C10025, doi:10.1029/2007JC004408, 2008.

Toffolon, M. and Savenije, H. H. G.: Revisiting linearized onedimensional tidal propagation, J. Geophys. Res., 116, C07007, doi:10.1029/2010JC006616, 2011.

Toffolon, M., Vignoli, G., and Tubino, M.: Relevant parameters and finite amplitude effects in estuarine hydrodynamics, J. Geophys. Res., 111, C10014, doi:10.1029/2005JC003104, 2006.

Van Rijn, L. C.: Analytical and numerical analysis of tides and salinities in estuaries; part I: tidal wave propagation in convergent estuaries, Ocean Dynam., 61, 1719-1741, doi:10.1007/s10236011-0453-0, 2011.
Vignoli, G., Toffolon, M., and Tubino, M.: Non-linear frictional residual effects on tide propagation, in: Proceedings of XXX IAHR Congress, vol. A, 24-29 August 2003, Thessaloniki, Greece, 291-298, 2003.

Zhang, E. F., Savenije, H. H. G., Wu, H., Kong, Y. Z., and Zhu, J. R.: Analytical solution for salt intrusion in the Yangtze Estuary, China, Estuar. Coast. Shelf. S., 91, 492-501, 2011.

Zhang, E. F., Savenije, H. H. G., Chen, S. L., and Mao, X. H.: An analytical solution for tidal propagation in the Yangtze Estuary, China, Hydrol. Earth Syst. Sci., 16, 3327-3339, doi:10.5194/hess-16-3327-2012, 2012. 